\title{
Sharing High Growth across Generations: Pensions and Demographic Transition in China
}

\author{
By Zheng Song, Kuetil Storesletten, Yikai Wang, And Fabrizio Zilibotti*
}

\begin{abstract}
We analyze intergenerational redistribution in emerging economies with the aid of an overlapping generations model with endogenous labor supply. Growth is initially high but declines over time. A version of the model calibrated to China is used to analyze the welfare effects of alternative pension reforms. Although a reform of the current system is necessary to achieve financial sustainability, delaying its implementation implies large welfare gains for the (poorer) current generations, imposing only small costs on (richer) future generations. In contrast, a fully funded reform harms current generations, with small gains to future generations. (JEL E13, H55, J11, O11, O15, P24, P36)
\end{abstract}

\begin{abstract}
number of emerging economies are experiencing fast income growth and convergence to developed economies, significantly improving the average living standards of their populations. Their success is often accompanied by increasing disparities, of which intergenerational inequality is an important component. In China, for instance, the present value of earnings for a worker who entered the labor force in 2000 is on average about six times as large as that of a worker who entered in 1970, when China was one of the poorest countries in the world. While young Chinese workers today face much better prospects than did their parents, poverty among the elderly is pervasive, aggravated by the gradual demise of traditional
\end{abstract}

\footnotetext{
* Song: The University of Chicago Booth School of Business, 5807 South Woodlawn Ave., Chicago, IL 60637 (e-mail: zheng.song@chicagobooth.edu); Storesletten: Department of Economics, University of Oslo, P.O. Box 1095 Blindern, N-0317 Oslo, Norway (e-mail: kjetil.storesletten@econ.uio.no); Wang: Department of Economics, University of Oslo, P.O. Box 1095 Blindern, N-0317 Oslo, Norway (e-mail: yikaikanewang@gmail.com); Zilibotti: Department of Economics, University of Zurich, Schnberggasse 1, CH-8001 Zurich, Switzerland (e-mail: fabrizio. zilibotti@econ.uzh.ch). We thank three referees and Philippe Aghion, Ingvild Almås, Chong-En Bai, Jimmy Chan, Martin Eichenbaum, Vincenzo Galasso, Chang-Tai Hsieh, Andreas Itten, Åshild Auglænd Johnsen, Dirk Krueger, Albert Park, Torsten Persson, Luigi Pistaferri, and seminar participants at the conference China and the West 1950-2050: Economic Growth, Demographic Transition and Pensions (University of Zurich, November 21, 2011), China Economic Summer Institute 2012, Chinese University of Hong Kong, Goethe University of Frankfurt, Hong Kong University, London School of Economics, Northwestern University, Peking University, Princeton University, Shanghai University of Finance and Economics, Stanford University, Tsinghua Workshop in Macroeconomics 2011, Università della Svizzera Italiana, University of Bergen, University of Chicago Booth, University of Mannheim, University of Pennsylvania, and University of Toulouse. Song acknowledges financial support from Chicago Booth and the China's Social Science Foundation (Grant No. 122D074). Storesletten acknowledges financial support from the ERC Advanced Grant Macroinequality-324085 and ESOP. Wang acknowledges financial support from the Swiss National Science Foundation (grant no. 100014-122636) and ERG Advanced Grant Microinequality-324085. Zilibotti acknowledges financial support from the ERC Advanced Grant IPCDP-229883.

Go to http://dx.doi.org/10.1257/mac.20130322 to visit the article page for additional materials and author disclosure statement(s) or to comment in the online discussion forum.
} 
forms of family insurance (Almås and Johnsen 2013; Park et al. 2012; Yang 2011; and Yang and Chen 2010).

In this paper, we study how alternative pension systems enable different generations to share the benefits of high growth in emerging countries. We construct an overlapping generation (OLG) model where the economy is initially on a fast convergence trajectory, followed by a slowdown as steady state is approached. We calibrate the model to China based on our earlier work in Song, Storesletten, and Zilibotti (2011), henceforth, SSZ. The model embeds key trends of the growth experience of China: a demographic transition, rural-urban migration, fast wage growth - expected to slow down in future, and financial market imperfections which repress the rate of return on households' savings.

We use the theory to assess the financial sustainability and welfare properties of alternative reforms. In line with previous studies (e.g., Sin 2005), we find that the current pension system is not financially sustainable, due to the unfavorable demographic transition that will increase the old age dependency ratio in coming years. The welfare effects of alternative sustainable reforms are evaluated from the perspective of a benevolent planner who weighs the utility of different generations with a geometrically declining weight. We take as a conservative benchmark a highly forward-looking (low-discount) planner who has no desire to redistribute resources across generations in steady state. We show that in emerging economies even this planner would like to redistribute resources to early generations because these earn much lower wages than future generations. In fact, her optimal policy involves paying generous pensions to the generations who are currently working or already retired, and negative pensions to subsequent generations. ${ }^{1}$

We compare the optimal policy to (sustainable) pension reforms that are being discussed in the policy debate. We start with an immediate reform adjusting benefits so as to make the system long-run sustainable, in the sense that the benefits and taxes would not need any future adjustment. This policy, which we label as the benchmark reform, involves a draconian permanent reduction in the replacement rate, from 60 to 39.1 percent, for all workers retiring after 2012 without reneging on the outstanding obligations to current retirees. This implies the accumulation of a large pension fund until 2052 to pay for the pensions of future generations retiring in times when the dependency ratio will be very high. The benchmark reform entails large welfare losses relative to the optimal policy, as it cuts pensions for the transition generations, while the planner would like to increase redistribution towards them.

We consider three alternative reforms. The first reform is a delayed reform, by which the current rules of the Chinese system remain in place until a future date $T$. Then, benefits are permanently reduced so as to balance the pension system in the long run. The length of the delay is chosen so as to maximize the low-discount planner's utility. The optimal delay is until 2050, and this policy yields large welfare gains for the transition generations relative to the benchmark reform in 2013. The cohorts retiring between 2013 and 2050 would enjoy welfare gains equivalent,

\footnotetext{
${ }^{1}$ In our calibration, the low-discount planner has an annual discount rate of 0.5 percent. We show that the drive for redistribution is stronger with a more impatient planner who is endowed, following Nordhaus (2007), with a social discount rate equal to the market interest rate.
} 
on average, to a 15.9 percent increase in their lifetime consumption. Later cohorts would only suffer small losses in the form of a slightly lower replacement ratio (and by assumption, all those who retired by 2012 are unaffected).

The second reform is a fully funded $(F F)$ reform that replaces the defined benefit transfer-based pension with a fully funded individual account system. To honor existing obligations, the government issues bonds to compensate current workers and retirees for their past contributions. A standard trade-off emerges: all generations retiring after 2059 benefit from the FF reform, whereas earlier generations lose. On the one hand, the FF reform reduces tax distortions on labor supply. On the other hand, it eliminates a redistributive policy that the planner values. We find that both the low-discount planner and, a fortiori, the Nordhaus planner prefer the delayed reform to the FF reform.

The third reform is switching to an unfunded pay-as-you-go (PAYGO) system where the replacement rate is endogenously determined by the dependency ratio, subject to a sequence of balanced budget conditions for the pension system. Given the demographic transition of China, the PAYGO system yields very generous pensions to early cohorts at the expense of the generations retiring after 2045. This reform yields substantial welfare gains by allowing the poorer current generations to share the benefits of high wage growth with the richer generations entering the labor market when China is a mature economy. The gains outweigh the losses originating from the larger labor supply distortion relative to the FF reform.

The results above accrue in an otherwise standard model. We show that in a mature economy where wages grow at a constant 2 percent per year, the planner would prefer a FF reform (or, alternatively, the immediate draconian reform) to a delayed reform or to a pure PAYGO system.

The normative predictions of our analysis run against the common wisdom that switching to a prefunded pension system is the best response for emerging economies facing adverse demographic dynamics. For instance, Feldstein (1999); Feldstein and Liebman (2006); and Dunaway and Arora (2007) argue that a fully funded reform is the best viable option for China. On the contrary, our policy recommendations are in line with Barr and Diamond (2008), who argue against reforming the pension system in the direction of pre-funded individual accounts.

Our results hinge on two typical features of emerging economies: a high wage growth during transition and a low rate of return on savings (in spite of high returns on investments). In the Chinese case, the forecast of a high wage growth reflects the fact that China's GDP per capita is still below 20 percent of the US level, leaving ample room for further convergence in technology and productivity. The low rate of return on savings reflect the well-documented fact that China suffers from severe financial market underdevelopment. For instance, Allen, Qian, and Qian (2005) document that China has poor investor protection, weak accounting standards, and a large share of nonperforming loans relative to its level of development. ${ }^{2}$ Our analysis

\footnotetext{
${ }^{2}$ Different from us, Feldstein (1999) assumes that the Chinese government has access to a risk-free annual rate of return on the pension fund of 12 percent. Unsurprisingly, he finds that a fully funded system that collects pension contributions and invests these funds at such a remarkable rate of return will dominate a PAYGO pension system that implicitly delivers the same rate of return as aggregate wage growth.
} 
illustrates a general point that applies to fast-growing emerging economies. Even for economies that are dynamically efficient, the combination of (i) a prolonged period of high wage growth and (ii) a low return on financial savings makes it possible to run a relatively generous pension system over the transition without imposing a large burden on future generations.

We abstract from some potentially important features. First, we consider neither idiosyncratic nor intergenerational risk. Both sources of risk are important and difficult to insure in emerging economies, strengthening the case for a nonfunded pension system (see Krueger and Kubler 2006; and Nishiyama and Smetters 2007). Second, we ignore within-cohort inequality. In reality, public pensions also provide some intragenerational redistribution. Last but not least important, we do not consider altruism within families. Public pensions could crowd out private transfers from children to the elderly, reducing the social value of pensions. Although incorporating within-family intergenerational transfers could weaken some of our results, such arrangements appear to be limited and declining over the process of economic development. Cai, Giles, and Meng (2006) document that, although retirees in urban China receive transfers from their children in response to negative income shocks (e.g., pension arrears), such transfers provide only very limited insurance. For instance, when income is close to the poverty line, a one yuan temporary reduction in income leads to an increase in net transfers between 10 and 16 cents. Their study concludes that improving the public pension system is unlikely to lead to any significant crowding out of private transfers. This conclusion is shared by Park et al. (2012) who add that, irrespective of the public pension system, the effectiveness of the informal private insurance system is set to decline in future (as it did, for instance, in the recent history of Latin America), since the elderly will have fewer children and more of them will live separately from their children (see also Yang and Chen 2010; and Calvo and Williamson 2008).

The paper is structured as follows. Section I presents the model and derives some normative implications. Section II calibrates the model to China, specifying the demographic dynamics, an exogenous wage growth process and a set of pension rules. Section III studies the welfare effects of alternative pension reforms. Section IV performs sensitivity analysis. Section V extends the analysis to a rural pension system and Section VI concludes. The online Appendix contains some technical material and a description of the general equilibrium model based on SSZ upon which the forecasts for wages and interest rates are based.

\section{Model}

This paper constructs a multiperiod OLG model to evaluate quantitatively the welfare implications of alternative pension reforms of China. The model is close in spirit to Auerbach and Kotlikoff (1987); Conesa and Garriga (2008); Conesa and Krueger (1999); Huang, Imrohoglu, and Sargent (1997); and Storesletten (2000).

\section{A. Household Problem}

The model economy is populated by a sequence of overlapping generations of agents. Each agent lives up to $J+J_{C}$ years and has an unconditional probability 
of surviving until age $j$ equal to $s_{j}$. During their first $J_{C}-1$ years (childhood), agents are economically inactive, make no choices, and do not derive any utility. Preferences are defined over consumption and leisure, and are represented by a standard lifetime utility function,

$$
U_{t}=\sum_{j=0}^{J} s_{j} \beta^{j}\left(\log \left(c_{t, j}\right)-\frac{\left(h_{t, j}\right)^{1+\frac{1}{\theta}}}{1+\frac{1}{\theta}}\right),
$$

where $\beta$ is the discount factor, $c$ is consumption, and $h$ is labor supply. Here, $t$ denotes the period in which the agent turns adult (i.e., becomes economically active), and $j$ is the number of years since entering adult life. Thus, $U_{t}$ is the discounted utility of an agent born in period $t-J_{C}$.

Workers are active until age $J_{W}$. For simplicity, we abstract from an endogenous choice of retirement. Incorporating endogenous retirement would require a more sophisticated model of labor supply, including nonconvexities in labor market participation and declining health and productivity in old age, as in e.g. French (2005) and Rogerson and Wallenius (2009). Since China has a mandatory retirement policy, the assumption of exogenous retirement seems reasonable. After retirement, agents receive pension benefits until death. Wages are subject to proportional social security taxes. Adult workers and retirees can borrow and deposit their savings with banks paying a gross annual interest rate $R$. A perfect annuity market allows agents to insure against uncertainty about the time of death.

Agents maximize $U_{t}$, subject to a lifetime budget constraint,

$$
\sum_{j=0}^{J} \frac{s_{j}}{R^{j}} c_{t, j}=\sum_{j=0}^{J_{W}} \frac{s_{j}}{R^{j}}\left(1-\tau_{t, j}\right) \varpi_{j} \eta_{t} w_{t+j} h_{t, j}+\sum_{j=J_{W}+1}^{J} \frac{s_{j}}{R^{j}} b_{t, j},
$$

where $t+j$ denotes time, $b_{t, j}$ denotes the pension benefit accruing in period $t+j$ to a person who became adult in period $t, w_{t+j}$ is the wage rate per efficiency unit at $t+j, \eta_{t}$ denotes the human capital specific to the cohort turning adult in $t, \tau_{t, j}$ is the labor income tax, and $\varpi_{j}$ is the efficiency units per hour worked for a worker with $j$ years of experience capturing the experience-wage profile. We abstract from within-cohort differences in human capital. Thus, $\left(1-\tau_{t, j}\right) \varpi_{j} \eta_{t} w_{t+j}$ is the aftertax hourly wage rate in period $t+j$ for a worker belonging to cohort $t$.

\section{B. Optimal Intergenerational Redistribution for an Emerging Economy}

To start with, we characterize the optimal pension policy which maximizes the utility of a benevolent social planner who cares about all present and future generations, and discounts the future generations' utilities geometrically with a discount factor $\phi \in(0,1)$. The purpose is to illustrate the main point of the paper, namely, that in emerging economies with fast but declining wage growth, even a social planner with a very low social discount rate wishes to redistribute resources from future to current generations. Moreover, the optimal redistribution can be implemented by a pension system that yields a declining sequence of replacement rates. 
The key assumption is that the wage growth is relatively fast in the beginning, and eventually converges to a steady-state growth rate $g$. As discussed in the introduction, this captures a salient feature of emerging economies. To convey the main message, we focus in this section on an economy in which wages grow at the rate $\tilde{g}>g$ until period $T$ (where $T>J$ ), and at the rate $g$ thereafter. The insights generalize to arbitrary wage sequences featuring a decreasing growth rate. Again for simplicity, we set $\varpi_{j}=\eta_{t}=s_{j}=1 .{ }^{3}$

The optimal allocation ( first best) maximizes

$$
V_{0}=\sum_{t=0}^{\infty} \mu_{t} \phi^{t} U_{t},
$$

where $U_{t}$ is defined in equation $(1)$ and $\mu_{t}$ is the population size of the cohort entering the labor market in period $t .{ }^{4}$ The maximization is subject to the following resource constraint:

$$
\sum_{t=0}^{\infty} \frac{\mu_{t}}{R^{t}} \sum_{j=0}^{J} \frac{c_{t, j}}{R^{j}}=A_{0}+\sum_{t=0}^{\infty} \frac{\mu_{t}}{R^{t}} \sum_{j=0}^{J_{w}} \frac{w_{t+j} h_{t, j}}{R^{j}},
$$

where $A_{0}$ denotes the initial planner's wealth net of promises to generations that enter the labor before time zero. Note that, for the resource constraint to be well-defined, we must assume that, in the long run, $R>(1+g)(1+n)$, where $n$ is the long-run population growth rate. This constraint guarantees that the economy is dynamically efficient. Moreover, we assume that $\phi<(1+n)^{-1}$, so as to ensure that the transversality condition of the planner's problem holds. Standard analysis yields the first-best allocation:

$$
\begin{aligned}
& c_{t, 0}=\lambda^{-1}(\phi R)^{t}, \\
& c_{t, j}=c_{t, 0}(\beta R)^{j}, \quad \text { for } \quad j \in\{1,2, \ldots, J\}, \\
& h_{t, j}=\left(\frac{w_{t+j}}{c_{t, j}}\right)^{\theta}, \quad \text { for } j \in\left\{0,1, \ldots, J_{w}\right\},
\end{aligned}
$$

where $\lambda$ is the Lagrange multiplier associated with the resource constraint (note that $\lambda$ is inversely related to $A_{0}$ ). The optimal consumption sequence is independent of the wage sequence. Over the life cycle the planner chooses the same consumption growth as do individuals (see equation (6)), whereas consumption grows across cohorts by the factor $\phi R$ (see equation (5)), independently of the wage dynamics. Finally, labor supply is increasing the larger is the wage relative to consumption (see equation (7)).

\footnotetext{
${ }^{3}$ This amounts to abstracting from human capital accumulation, a rising age profile of wages, and mortality before age $J$. This is without loss of generality and the results are robust to allowing $\varpi_{j} \neq 1, \eta_{t} \neq 1$, and $s_{j}<1$. In the quantitative analysis below, we restore all these features.

${ }^{4}$ We ignore the generations born before $t=0$, since we assume that the planner cannot change the utility promised to these generations.
} 
Next, suppose that the planner faces a standard implementability constraint: any (Ramsey) allocation must be a competitive equilibrium. Suppose, in addition, that the only instrument at her disposal is a pension system comprising a sequence of taxes and pension replacement rates $\left\{\zeta_{t}, \tau_{t}\right\}_{t=0}^{\infty}$, where cohort $t$ 's labor income is taxed at the flat rate $\tau_{t}$, and the cohort receives a pension $b_{t, j}$. To achieve an analytical characterization, it is convenient to define cohort $k$ 's pension replacement rate $\zeta_{k}$ as the ratio between the present value of its pensions and that of its after-tax labor income: $\zeta_{k}=\left(\sum_{j=J_{w}+1}^{J} b_{k, j} R^{-j}\right) /\left(\sum_{j=0}^{J_{w}}\left(1-\tau_{t}\right) w_{k+j} \bar{h}_{k, j} R^{-j}\right)$, where $\bar{h}_{k, j}$ is the average labor supply of workers of cohort $k$ with experience $j$.

The following proposition (proof in the online Appendix) establishes that the first best can be implemented by setting the tax rate to zero and choosing a suitable replacement rate sequence.

PROPOSITION 1: The first-best allocation can be implemented by a Ramsey sequence of cohort-specific taxes and pension replacement rates. These sequences have the following characterization: $(i)$ Taxes are zero in all periods, $\tau_{t, j}=0$ for all t and j; (ii) The pension replacement rate sequence is:

$$
\frac{1+\zeta_{t+1}}{1+\zeta_{t}}=\left(\frac{\phi R}{1+g}\right)^{1+\theta} \times\left(\frac{1+g}{1+\tilde{g}}\right)^{1+\theta} \times F(t),
$$

where $F(t)$ is a continuous nondecreasing function of the birth date $t$ such that $F(t)=1$ for all $t \leq T-J_{w}, F(t)=\left(\frac{1+\tilde{g}}{1+g}\right)^{1+\theta}>1$ for all $t>T$ and $F(t)$ is increasing in $t$ for intermediate values. The expressions for $F(t)$ and $\zeta_{0}$ are given in the online Appendix.

The particular case in which $\phi=(1+g) / R$ is especially revealing. In this case, the planner would engage in no intergenerational redistribution in a mature economy where $\tilde{g}=g \cdot{ }^{5}$ However, if $\tilde{g}>g$, the benefit sequence is monotonically decreasing during the transition. Thus, the optimal pension system redistributes resources from the steady-state generations to the transition generations.

In Proposition 1, some cohorts may earn negative pensions. It is straightforward to extend the result to a setting where pensions are constrained to be nonnegative (see Corollary 2 in the online Appendix). In this case, pensions may be set to zero for some cohorts, and so these cohorts face positive social security taxes. Finally, the theory yields the normative prediction that no generation should ever be taxed when working and earn pension benefits in old age, as this creates an inefficient labor supply wedge.

\section{Parametrizing the Model}

This section parametrizes the model. We first describe the demographic model, then calibrate the rest of the model, and finally specify a pension system.

\footnotetext{
${ }^{5}$ To see why, note that the right-hand side of equation (8) would be unity if $\tilde{g}=g$, so $\zeta_{t}$ must be constant.
} 


\section{A. Demographic Model}

Since China faces a major demographic transition that affects the viability of the pension system, we construct, in this section, a detailed demographic model. We assume an exogenous population dynamics model and provide a detailed account of internal rural-urban migration since this has important effects on the sustainability of the system.

Throughout the 1950s and 1960s, the total fertility rate (henceforth, TFR) of China was between five and six. High fertility, together with declining mortality, brought about a rapid expansion of the total population. The 1982 census estimates a population size of one billion, 70 percent higher than in the 1953 census. The view that a booming population is a burden on the development process led the government to introduce measures to curb fertility during the 1970s, culminating in the one-child policy of 1978. This policy imposes severe sanctions on couples having more than one child. The policy underwent a few reforms and is currently more lenient to rural families and ethnic minorities. Today's TFR is below replacement level, although there is no consensus about its exact level. Estimates based on the 2000 census and earlier surveys range between 1.5 and 1.8 (e.g., Zhang and Zhao 2006). Recent estimates suggest a TFR of about 1.6 (Zeng 2007).

Natural Population Projections.-We consider, first, a model without rural-urban migration, which is referred to as the natural population dynamics. We break down the population by birth place (rural versus urban), age, and gender. The initial population size and distribution are matched to the adjusted 2000 census data. ${ }^{6}$ There is consensus among demographers that birth rates have been underreported, causing a deficit of 30-37 million children in the 2000 census. ${ }^{7}$ To heed this concern, we take the rural-urban population and age-gender distribution from the 2000 census-with the subsequent National Bureau of Statistics (NBS) revisions - and then amend this by adding the missing children for each age group, according to the estimates of Zhai and Chen (2007) (see also Goodkind 2004).

The initial group-specific mortality rates are also estimated from the 2000 census, yielding a life expectancy at birth of 71.1 years, which is very close to the World Development Indicator figure in the same year (71.2). Life expectancy is likely to continue to increase as China becomes richer. Therefore, we set the mortality rates in 2020, 2050, and 2080 to match the demographic projection by Zeng (2007) and use linear interpolation over the intermediate periods. We assume no further change after 2080. This implies a long-run life expectancy of 81.9 years.

The age-specific urban and rural fertility rates for 2000 and 2005 are estimated using the 2000 census and the 2005 one-percent population survey, respectively. We interpolate linearly the years 2001-2004, and assume age-specific fertility rates to

\footnotetext{
${ }^{6}$ The 2000 census data are broadly regarded as a reliable source (see, e.g., Lavely 2001; Goodkind 2004). The total population was originally estimated to be 1.24 billion, later revised by the NBS to 1.27 billion (see the Main Data Bulletin of 2000 National Population Census). The NBS also adjusted the urban-to-rural population ratio from 36.9 to 36 percent.

${ }^{7}$ See Goodkind (2004). A similar estimate is obtained by Zhang and Cui (2003), who use primary school enrolments to back out the actual child population.
} 
remain constant at the 2005 level over the period 2006-2012. This yields average urban and rural TFRs of 1.2 and 1.98, respectively. ${ }^{8}$ Between 2013 and 2050, we assume age-specific fertility rates to remain constant in rural areas. In November 2013, the third plenum of the Chinese Communist Party's 18th Party Congress announced the plan allowing couples to have two children if one of them is an only child. This policy has been rapidly implemented by provinces. Zeng (2007) estimates that such a policy would increase the urban TFR from 1.2 to 1.8 (second scenario in Zeng 2007). This is in line with the explicit target of the Chinese authorities, as outlined by the National Health and Family Planning Commission (source: Xinhuanet November 15, 2013).

A long-run TFR of 1.8 implies an ever-shrinking population. We follow the United Nations population forecasts and assume that in the long run the population will be stable. This requires that the TFR converges to 2.08 , which is the reproduction rate in our model, in the long run. In order to smooth the demographic change, we assume that both rural and urban fertility rates start growing in 2051, and we use a linear interpolation of the TFRs for the years 2051-2099. Since long-run forecasts are subject to large uncertainty, we also consider an alternative scenario with lower fertility.

Rural-Urban Migration.-Rural-urban migration has been a prominent feature of the Chinese economy since the 1990s. There are two categories of rural-urban migrants. The first category comprises all individuals who physically move from rural to urban areas. It includes both people who change their registered permanent residence (i.e., hukou workers) and people who reside and work in urban areas but retain an official residence in a rural area (non-hukou urban workers). 9 The second category comprises all individuals who do not move but whose place of registered residence switches from being classified as rural into being classified as urban. ${ }^{10} \mathrm{We}$ define the sum of the two categories as the net migration flow (NMF).

We propose a simple model of migration where the age- and gender-specific emigration rates are fixed over time. Although emigration rates are likely to respond to the urban-rural wage gap, pension and health care entitlements for migrants, the rural old-age dependency ratio, and so on, we will abstract from this and maintain that the demographic development only depends on the age distribution of rural

\footnotetext{
${ }^{8}$ The acute gender imbalance is taken into account in our model. However, demographers view it as unlikely that such imbalance will persist at the current high levels. Following Zeng (2007), we assume that the urban gender ratio will decline linearly from 1.145 to 1.05 from 2000 to 2030, and that the rural gender imbalance falls from 1.19 to 1.06 over the same time interval. No change is assumed thereafter. Our results are robust to plausible changes in the gender imbalance.

${ }^{9}$ There are important differences across these two subcategories. Most nonresident workers are currently not covered by any form of urban social insurance including pensions. However, some relaxation of the system has occurred in recent years. The system underwent some reforms in 2005, and in 2006 the central government abolished the hukou requirement for civil servants (Chan and Buckingham 2008). Since there are no reliable estimates of the number of non-hukou workers, and in addition there is uncertainty about how the legislation will evolve in future years, we decided not to distinguish explicitly between the two categories of migrants in the model. This assumption is of importance with regard to the coverage of different types of workers in the Chinese pension system. We return to this discussion below.

${ }^{10}$ This was a sizeable group in the 1990s: according to China Civil Affairs Statistical Yearbooks, a total of 8,439 new towns were established from 1990 to 2000 and 44 million rural citizens became urban citizens (Hu 2003). However, the importance of reclassified areas has declined after 2000. Only 24 prefectures were reclassified as prefecture-level cities in 2000-2009, while 88 prefectures were reclassified in 1991-2000.
} 
workers. It is generally difficult, even for developed countries, to predict the internal migration patterns (see Kaplan and Schulhofer-Wohl 2012). In China, pervasive legal and administrative regulations compound this problem.

We start by estimating the NMF and its associated distribution across age and gender. This estimation is the backbone of our projection of migration and the implied rural and urban population dynamics. We use the 2000 census to construct a projection of the natural rural and urban population until 2005 based on the method described in Section IIA. We can then estimate the NMF and its distribution across age groups by taking the difference between the 2005 projection of the natural population and the realized population distribution according to the 2005 survey. ${ }^{11}$ The technical details of the estimation can be found in the online Appendix.

According to our estimates, the overall NMF between 2001 and 2005 was 88 million, corresponding to 10.9 percent of the rural population in $2000 .{ }^{12}$ Survey data show that the urban population grows at an annual 4.1 percent rate between 2000 and 2005. Hence, 89 percent of the Chinese urban population growth during those years appears to be accounted for by rural-urban migration. Our estimate implies an annual flow of 17.6 million migrants between 2001 to 2005, equal to an annual 2.3 percent of the rural population. This figure is in line with estimates of earlier studies. For instance, Hu (2003) estimates an annual flow between 17.5 and 19.5 million in the period 1996-2000.

The estimated age-gender-specific migration rates are shown in Figure 1 . Both the female and male migration rates peak at age 15 , with 15.4 percent for females and 12.1 percent for males. The migration rate falls gradually at later ages, remaining above 1 percent until age 39 for females and until age 40 for males. Migration becomes negligible after age forty.

To incorporate rural-urban migration in our population projection, we make two assumptions. First, the age-gender-specific migration rates remain constant after 2005 at the level of our estimates for the period 2000-2005. Second, once the migrants have moved to an urban area, their fertility and mortality rates are assumed to be the same as those of urban residents.

Figure 2 shows the resulting projected population dynamics (solid lines). For comparison, we also plot the natural population dynamics (i.e., the population model without migration [dotted lines]). The rural population declines throughout the whole period. The urban population share increases from 51 percent in 2011 to 81 percent in 2050 and to over 95 percent in 2100 . In absolute terms, the urban population increases from 470 million in 2000 to its long-run 1.1 billion level in 2050.

\footnotetext{
${ }^{11}$ Our method is related to Johnson (2003), who also exploits natural population growth rates. Our work is different from Johnson's in three respects. First, his focus is on migration across provinces, whereas we estimate rural-urban migration. Second, Johnson only estimates the total migration flow, whereas we obtain a full age-gender structure of migration. Finally, our estimation takes care of measurement error in the census and survey (see discussion above), which were not considered in previous studies.

${ }^{12}$ There are a number of inconsistencies across censuses and surveys. Notable examples include changes in the definition of city population and urban area (see, e.g., Zhou and Ma 2003; Duan and Sun 2006). Such inconsistencies could potentially bias our estimates. In particular, the definition of urban population in the 2005 survey is inconsistent with that in the 2000 census. In the 2000 census, urban population refers to the resident population (changzhu renkou) of the place of enumeration who had resided there for at least six months on census day. The minimum requirement was removed in the 2005 survey. Therefore, relative to the 2005 survey definition, rural population tends to be over-counted in the 2000 census. This tends to bias our NMF estimates downward.
} 


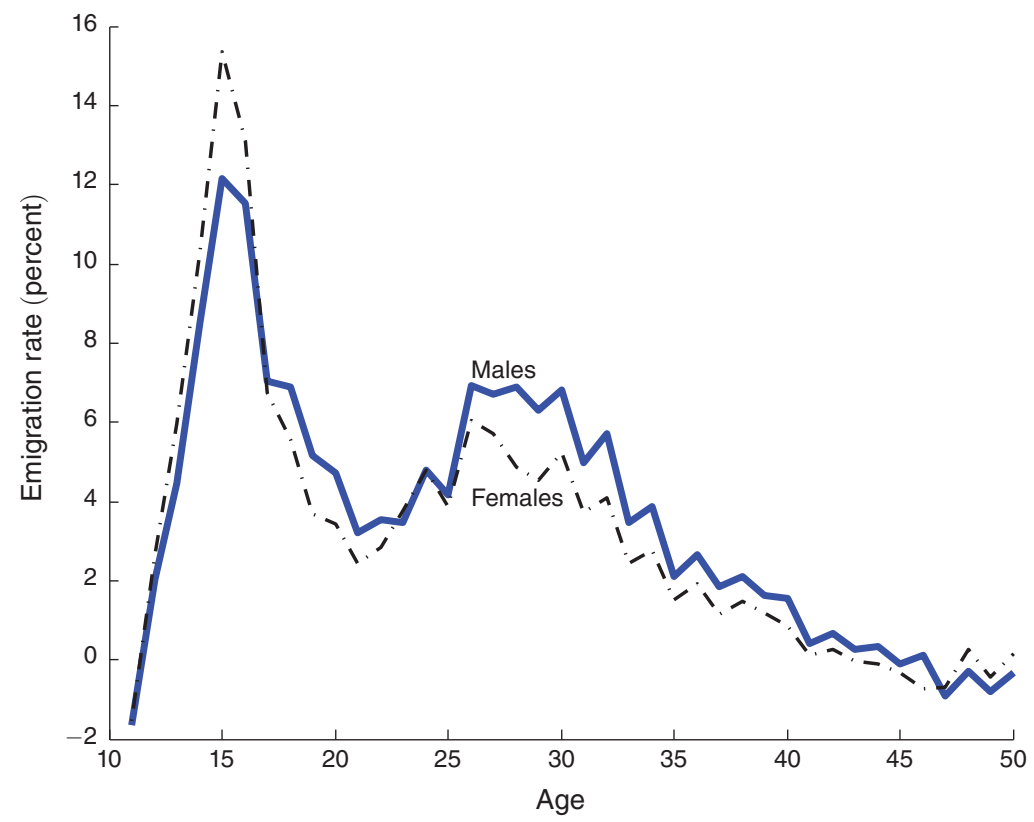

Figure 1. Emigration Rates From Rural Areas by Age and Gender

Notes: The figure shows rural-urban migration rates by age and gender as a share of each cohort. The estimates are smoothed by five-year moving averages.

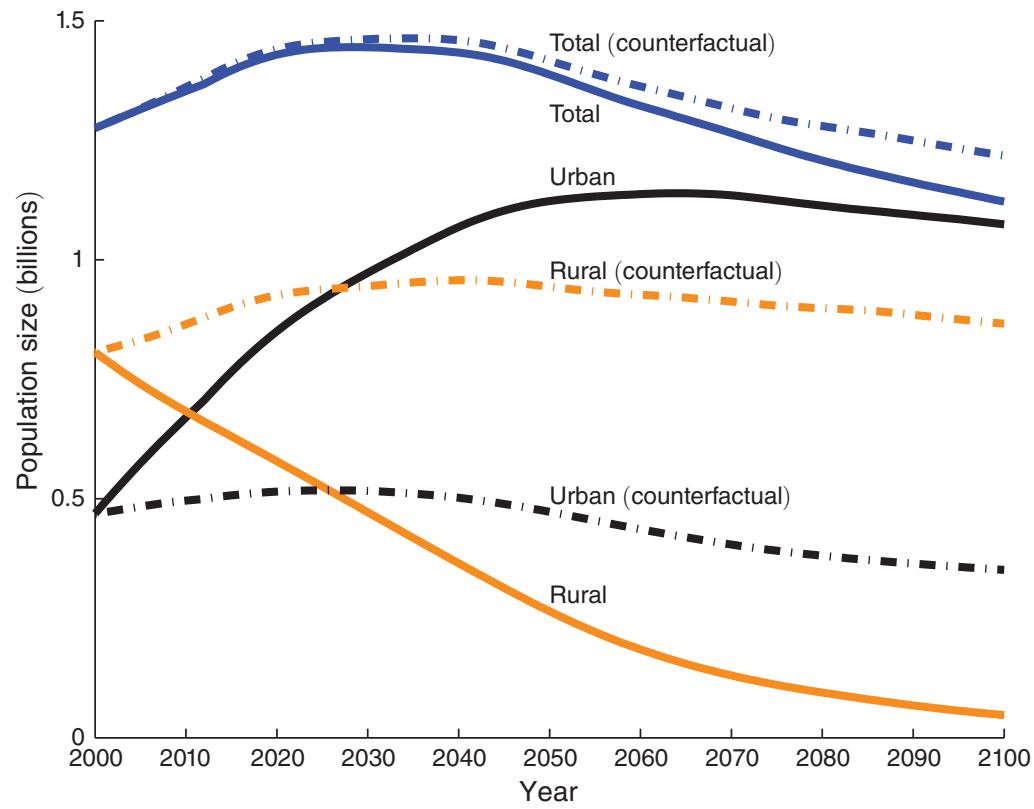

Figure 2. Population Dynamics of China

Notes: The figure shows the projected population dynamics for 2000-2100 (solid lines) broken down by rural and urban population. The dashed lines show the corresponding natural population dynamics (i.e., the counterfactual projection under a zero urban-rural migration scenario). 


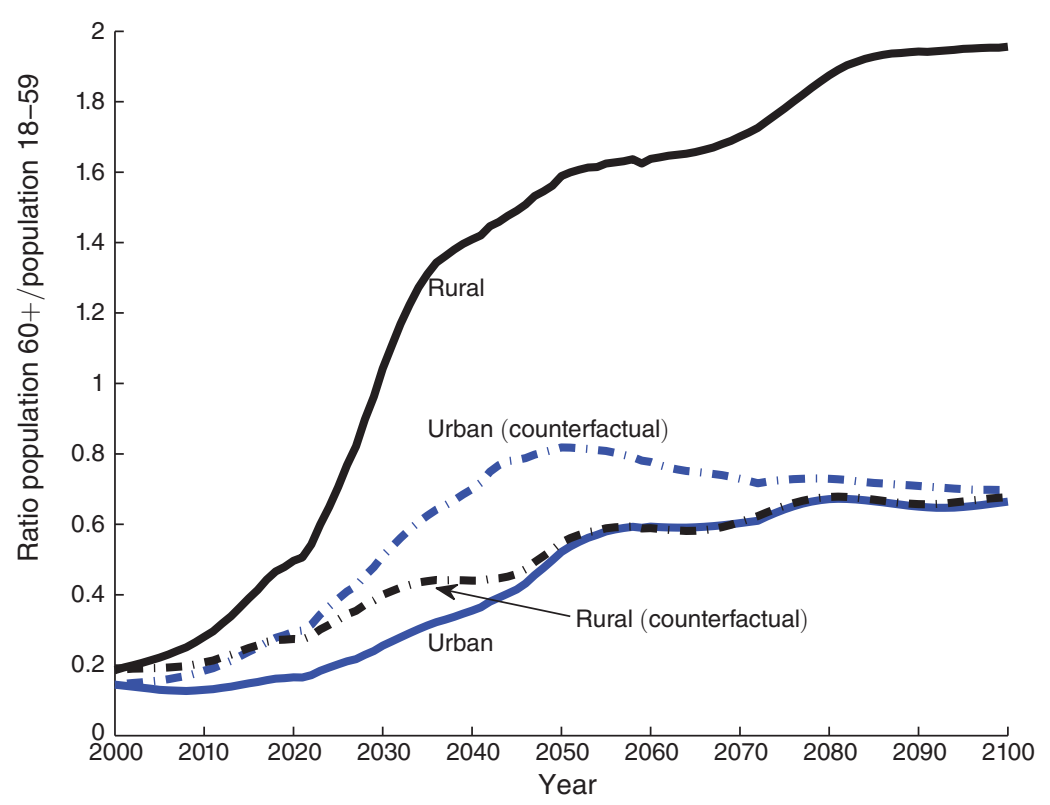

Figure 3. Projected Old-Age Dependency Ratios

Notes: The figure shows the projected old-age dependency ratios, defined as the ratio of population $60+$ over population 18-59, for 2000-2100 (solid lines) broken down on urban and rural population. The dashed lines show the corresponding ratios under the zero migration counterfactual (i.e., the natural population dynamics).

Between 2050 and 2100 there are two opposite forces that tend to stabilize the urban population: on the one hand, fertility is below replacement in urban areas until 2100; on the other hand, there is still sizeable immigration from rural areas.

Figure 3 plots the old-age dependency ratio (i.e., the number of retirees as percentage of individuals in working age [18-60]) broken down by rural and urban areas (solid lines). ${ }^{13}$ We also plot, for contrast, the old-age dependency ratio in the no migration counterfactual (dashed lines). Rural-urban migration is very important for the projection. The projected urban old-age dependency ratio is 52 percent in 2050 , but it would be as high as 82 percent in the no migration counterfactual. This is an important statistic, since the Chinese pension system only covers urban workers, so its sustainability hinges on the urban old-age dependency ratio.

\section{B. Calibration of Wage and Interest Rate Process}

In this section, we calibrate the wage and interest rate process. We set the agewage profile $\left\{\varpi_{j}\right\}_{j=23}^{59}$ equal to the one estimated by Song and Yang (2010) for Chinese urban workers. This implies an average annual return to experience of 0.5 percent.

\footnotetext{
${ }^{13}$ In China, the official retirement age is 55 for females and 60 for males. In the rest of the paper, we ignore this distinction and assume that all individuals retire at age 60 , anticipating that the age of retirement is likely to increase in the near future. We also consider the effect of changes in the retirement age.
} 
Urban hourly wages (holding human capital constant) are assumed to grow at 5.7 percent between 2000 and 2013. This is consistent with the estimate of Ge and Yang (2014) for workers with only middle school education. We base the future wage sequence - which is essential for the quantitative results of the paper-on the (smoothed) forecast generated by a calibrated dynamic general-equilibrium model with credit market imperfections close in spirit to SSZ. That model is laid out in detail in the online Appendix (see, especially, Figure III). This yields an annual growth of 4.9 percent for the period 2013-2031, followed by an annual growth of 3.6 percent for 2031-2040. After 2040, wages grow at 2 percent per year, in line with wage growth in the United States over the last century.

There has been substantial human capital accumulation in China over the last two decades. To incorporate this aspect, we assume that each generation has a cohortspecific education level, which is matched to the average years of education by cohort according to Barro and Lee (2013) — see Figure IV in the online Appendix. The values for cohorts born after 1990 are extrapolated linearly, assuming that the growth in the years of schooling ceases in year 2000 when it reaches an average of 12 years, which is the current level for the United States. We assume an annual return of 10 percent per year of education. ${ }^{14}$ Since younger cohorts have more years of education, wage growth across cohorts will exceed that shown in Figure IV (note though that the education level for an individual remains constant over each individual work life).

The average wage growth in the economy compounds the productivity growth per efficiency unit of labor shown in Figure III with the effect of increasing educational attainment of the labor force. In addition, there is a small effect arising from changes in the age composition of workers: as we shall see, the experience-wage profile is upward sloping, so an ageing workforce implies somewhat higher average wages. When all these effects are incorporated, the average annual growth rate in the period 2012-2050 is 4.8 percent. This is a conservative forecast in light of the wage growth over the last two decades (for example, Ge and Yang 2014, who estimate an annual 7.7 percent average wage growth in the period 1992-2007). However, our projected wage growth is in line with existing studies: Citibank forecasts an annual growth rate of GDP per capita of 5 percent over the period 2010-2050 (Buiter and Rahbari 2011, 63). If the labor share remained constant, wage growth should remain aligned with GDP growth. In Section IVA, we perform some sensitivity analysis of the speed of future wage growth.

The rate of return on capital is very large in China (Bai, Hsieh, and Qian 2006). However, these high rates of return appear to have been inaccessible to the government and to the vast majority of workers and retirees. Indeed, in addition to housing and consumer durables, bank deposits are the main asset held by Chinese households in their portfolio. For example, in 2002 more than 68 percent of households' financial assets were held in terms of bank deposits and bonds, and for the median decile of households this share is 75 percent (Chinese Household Income Project 2002, henceforth CHIP). Moreover, aggregate household deposits in Chinese banks amounted to 76.6 percent of GDP in 2009 (China Statistical Yearbook 2010). High

\footnotetext{
${ }^{14}$ Zhang et al. (2005) estimated returns to education in urban areas of six provinces from 1988 to 2001 . The average returns were 10.3 percent in 2001.
} 
rates of return on capital do not appear to have been available to the government, either. Its portfolio consists mainly of low-yield bonds denominated in foreign currency and equity in state-owned enterprises, whose rate of return is lower than the rate of return to private firms (Dollar and Wei 2007).

SSZ provides an explanation-based on large credit market imperfections-for why neither the government nor the workers have access to the high rates of return of private firms. In this section, we simply assume that the annual rate of return for private and government savings is $R=1.025$. We view a 2.5 percent annual return for the government savings as realistic. According to the National Council for Social Security Fund, the average share of pension funds invested in stock markets was 19 percent in 2003-2011. ${ }^{15}$ Assuming an average 6 percent annual return on stock and a 1.75 percent return on the remaining portfolio yields an average annual return of roughly 2.5 percent. This is also in line with the return on best-practice Western pension funds. For instance, the Credit Suisse Swiss Pension Fund has achieved a 2.25 percent annual rate of return between 2000-2012. Concerning the return on private savings, a one-year real deposit rate in Chinese banks - the most typical saving instrument of private agents-was 1.75 percent during 1998-2005 (nominal deposit rate minus CPI inflation). Given that some households have access to savings instruments that yield higher returns, a 2.5 percent return seems a plausible assumption also for private agents. Note that our economy is dynamically efficient. Assuming $R<1.02$ would imply that the rate of return is lower than the long-run growth rate of the economy, implying dynamic inefficiency. In such a scenario, there would be no need for a pension reform due to a well-understood mechanism (Abel et al. 1989).

In the online Appendix, we show that the wage rate dynamics in Figure III and the assumed interest rate path are a close approximation to the equilibrium outcome of a calibrated dynamic general equilibrium model similar to SSZ, but augmented with the demographic model outlined above and a pension system. In the general equilibrium model, the wage and interest rate sequences are sufficient to compute the optimal decisions of workers and retirees about consumption and labor supply, as well as the sequence of budget constraints faced by the government. The model in SSZ matches well a number of salient macroeconomic trends for the recent period: output growth, wage growth, return to capital, transition from state-owned to private firms, and foreign surplus accumulation. The calibrated model is shown to yield plausible growth forecasts (although these are obviously subject to great uncertainty). The growth rate of GDP per worker remains about 7.5 percent per year until 2020. After 2020, productivity growth is forecasted to slow down. On average, China is expected to grow at a rate of 6.5 percent between 2013 and 2040. The contribution of human capital is 0.8 percent per year, due to the entry of more educated young cohorts in the labor force. In this scenario, the GDP per capita in China will be 68 percent of the US level by 2040, remaining broadly stable thereafter.

\footnotetext{
${ }^{15}$ Source: http://www.ssf.gov.cn/xw/xw_gl/201205/t20120509_4619.html.
} 


\section{Calibration of Preferences and Wealth Distribution}

One period is defined as a year and agents can live up to 100 years $(J=100)$. The demographic process (mortality, migration, and fertility) is described in Section IIA. Agents become adult (i.e., economically active) at age $J_{C}=22$ and retire at age 60, which is the male retirement age in China (so $J_{W}=59$ ). ${ }^{16}$ Hence, workers retire after 38 years of work. The discount factor is set to $\beta=1.0164$ to capture the average urban household savings rate in China between 2000-2012 (i.e., 25 percent). This is slightly higher than the value estimated by Hurd (1989) for the United States (i.e., 1.011). As a robustness check, in Section IV we consider an alternative economy where $\beta$ is lower for all people born after 2013. The Frisch elasticity of labor supply in (1) is set to $\theta=0.5$, in line with standard estimates in labor economics (Keane 2011).

Finally, we set the initial distribution of household wealth to match the empirical distribution of financial wealth in 1995 in the CHIP. ${ }^{17}$ We exclude households with dependents over the age of 22, though the results are not sensitive to controls on family structure. Given the 1995 wealth distribution, we simulate the model over the 1995-2000 period, assuming an annual wage growth of 5.7 percent, excluding human capital growth. The distribution of private wealth in 2000 is then obtained endogenously.

\section{The Current Pension System}

In this section, we lay out a set of taxes and pension entitlements that replicate the main features of China's current pension system. A more comprehensive description of the Chinese system can be found in the online Appendix.

The current Chinese system was originally introduced in 1986 and underwent a major reform in 1997. Before 1986, urban firms (which were almost entirely state owned at that time) were responsible for paying pensions to their former employees. This enterprise-based system became untenable in a market economy where firms can go bankrupt and workers can change jobs. The 1986 reform introduced a defined benefits system whose administration was assigned to municipalities. The new system came under financial distress, mostly due to firms evading their obligations to pay pension contributions for their workers.

The subsequent 1997 reform reduced the replacement rates for future retirees and tried to enforce social security contributions more strictly. The 1997 system has two tiers (plus a voluntary third tier). The first is a standard transfer-based basic pension system with resource pooling at the provincial level. The second is an individual accounts system. However, as documented by $\operatorname{Sin}(2005,2)$, "the individual

\footnotetext{
${ }^{16}$ We have repeated the analysis assuming a retirement age of 57 for all workers. This is a weighted average of the male and female retirement age, according to the current statutory rules. The results are reported in the online Appendix. The fiscal imbalances of the system are larger. However, this does not change the main welfare results of the paper. We have opted for using a retirement age of 60 as a benchmark because we believe the pension age is likely to increase as the health of the Chinese population improves with economic progress.

${ }^{17}$ We exclude housing wealth in 1995 for two reasons. First, the data are highly uncertain. Second, the dynamics of housing wealth distribution are driven by valuation effects that reflect, partly, increasing cost of housing services. Including housing in the initial wealth distribution would have negligible consequences.
} 
accounts are essentially 'empty accounts' since most of the cash flow surplus has been diverted to supplement the cash flow deficits of the social pooling account." Due to its low capitalization, the system can be viewed as broadly transfer-based, although it permits, as does the US Social Security system, the accumulation of a trust fund to smooth the aging of the population. Since the individual accounts are largely notional, we decided to ignore any distinction between the different pension pillars in our analysis.

We model the pension system as a defined benefits plan, subject to the intertemporal budget constraint, (11). In the online Appendix, we discuss more explicitly how the institutional details are mapped into the model. In line with the actual Chinese system, pensions are partly indexed to wage growth. We approximate the benefit rule by a linear combination of the average earnings of the beneficiary at the time of retirement and the current wage of workers, with weights 60 and 40 percent, respectively. ${ }^{18}$ More formally, the pension received at period $t+j$ by an agent who worked until period $t+J_{W}$ (and who became adult in period $\left.t\right)$ is ${ }^{19}$

$$
b_{t, t+j}=q_{t+J_{W}} \cdot\left(0.6 \cdot \bar{y}_{t+J_{W}}+0.4 \cdot \bar{y}_{t+j-1}\right),
$$

where $j>J_{W}$, and $q_{t}$ denotes the replacement rate in period $t$ and $\bar{y}_{t}$ is the average pretax labor earnings for workers in period $t$ :

$$
\bar{y}_{t} \equiv \frac{w_{t} \sum_{j=0}^{J_{w}} \mu_{t-j} s_{j} \eta_{t-j} \varpi_{j} h_{t-j, t}}{\sum_{j=0}^{J w} \mu_{t-j} s_{j}},
$$

where $\mu_{t-j} s_{j}$ is the number of agents of cohort $t-j$ (i.e., who became economically active in period $t-j$ ) who have survived until period $t$. In line with the 1997 reform (see Sin 2005), we assume that pensioners retiring before 1997 continued to earn a 78 percent replacement rate throughout their retirement. Moreover, those retiring between 1997 and 2011 are entitled to a 60 percent replacement rate. We assume a constant social security tax $(\tau)$ equal to 20 percent, in line with the empirical evidence. ${ }^{20}$

The current pension system of China covers only a fraction of the urban workers. The coverage rate has grown from 45 percent in 2001 to 60 percent in 2011 (see China Statistical Yearbook 2012). In the baseline model, we therefore assume a constant coverage rate of 60 percent. Workers who are not covered neither pay the social security tax nor do they receive pensions.

\footnotetext{
${ }^{18}$ The current Chinese system specifies a partial indexation based on the increase in (regional) nominal wages. According to Sin (2005), the level of such indexation has ranged historically between 40 and 60 percent. In her study, she assumes a 60 percent indexation to nominal wage growth. Throughout our analysis, we abstract from inflation and assume a 40 percent indexation to real wage growth. Over the twenty years following the 2013 reform, the two approaches yield the same real pension growth as long as the annual inflation rate is 2.65 percent. However, the two approaches yield different indexation in the long run. Since any inflation forecast over long horizons would be speculative, we prefer to assume a real wage indexation, although this is not, strictly speaking, what the law says.

${ }^{19}$ Alternatively, the law of motion of pension benefits can be expressed as $b_{t, t+j}=b_{t+J_{W}+1}(0.6+0.4$ $\left.\times\left(\bar{y}_{t+j-1} / \bar{y}_{t+J_{W}}\right)\right)$. Note that the definition of the replacement rate in this section is different from that in the theoretical Section IB. To avoid confusion we use a different notation $\left(q_{k}\right.$ instead of $\left.\zeta_{k}\right)$.

${ }^{20}$ The statutory contribution rate including both basic pensions and individual accounts is 28 percent. However, there is evidence that a significant share of the contributions is evaded, even for workers who formally participated in the system. See the online Appendix for details.
} 
The coverage rate of migrant workers is a key issue. Since we do not have direct information about their coverage, we have simply assumed that rural immigrants get the same coverage rate as urban workers. This seems a reasonable compromise between two considerations. On the one hand, the coverage of migrant workers (especially low-skill non-hukou workers) is lower than that of nonmigrant urban residents; on the other hand, the total coverage has been growing since 1997. ${ }^{21}$

\section{E. The Government Budget Constraint}

The pension system is said to be financially balanced if, given an initial pension trust fund, $A_{0}$, the government intertemporal budget constraint holds, i.e.,

$$
\sum_{t=0}^{\infty} R^{-t}\left(\sum_{j=J_{W}+1}^{J} \mu_{t-j} s_{j} b_{t-j, t}-\tau_{t} \sum_{j=0}^{J_{W}} \mu_{t-j} s_{j} \varpi_{j} \eta_{t-j} w_{t} h_{t-j, t}\right) \leq A_{0} .
$$

We set the initial wealth, $A_{0}$, equal to 1 percent of GDP. This matches the observation from the National Statistics Bureau of China, according to which the pension trust fund amounted to 110 billion RMB in 2001. In a previous version of this paper, we assumed that all initial government wealth (amounting to 71 percent of GDP) can be committed to the pension system. In spite of the apparent large difference in initial wealth, the welfare effects of alternative reforms are almost identical. The main difference is that the size of the fiscal adjustment needed to balance the budget is smaller when the pension system has a larger initial fund.

\section{F. The Benchmark Reform}

Under our calibration of the model, the current pension system is not balanced. In other words, the intertemporal budget constraint, (11), would not be satisfied if the current rules were to remain in place forever. For the intertemporal budget constraint to hold, it is necessary either to reduce pension benefits or to increase contributions.

We construct a benchmark pension system to which we compare alternative reforms. To ensure that this system is financially viable, we assume that (i) the existing rules apply for all workers who are already retired by 2013; (ii) the social security tax remains constant at $\tau=20$ percent for all cohorts; (iii) for workers retiring in 2013 or later, the replacement rate is amended and set permanently to a new level $q$ which is the highest constant level consistent with the intertemporal budget constraint, (11). All households are assumed to anticipate that the benchmark reform will take place in 2013. We refer to such a scenario as the benchmark reform. ${ }^{22}$

The benchmark reform entails a large reduction in the replacement rate, from 60 to 39.1 percent. Namely, pensions must be cut by a third in order for the system to be financially sustainable. Such an adjustment is consistent with the existing estimates of

\footnotetext{
${ }^{21}$ According to a recent document issued by the National Population and Family Planning Commission, 28 percent of migrant workers are covered by the pension system (Table 5-1, 2010 Compilation of Research Findings on the National Floating Population).

${ }^{22}$ We cannot take as our benchmark an unbalanced system that retains the current statutory rules forever, since it would not make sense to compare its welfare properties with those associated with financially sustainable reforms.
} 
Panel A. Replacement rate by year of retirement

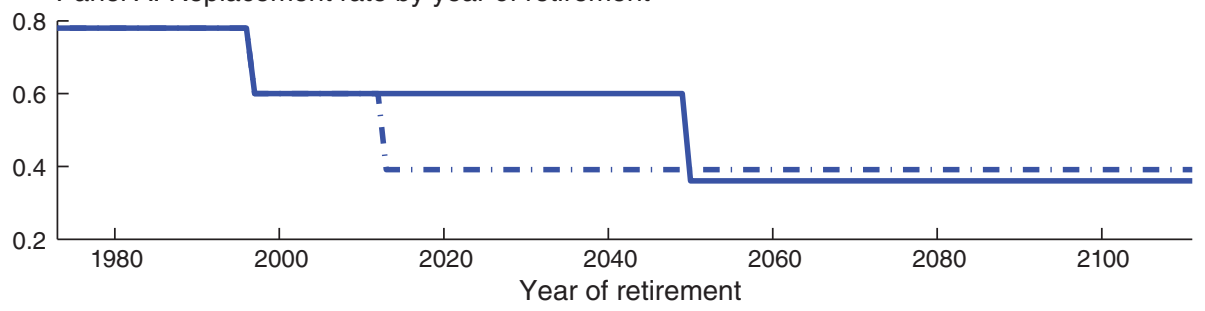

Panel B. Tax revenue and pension expenditures as shares of urban earnings

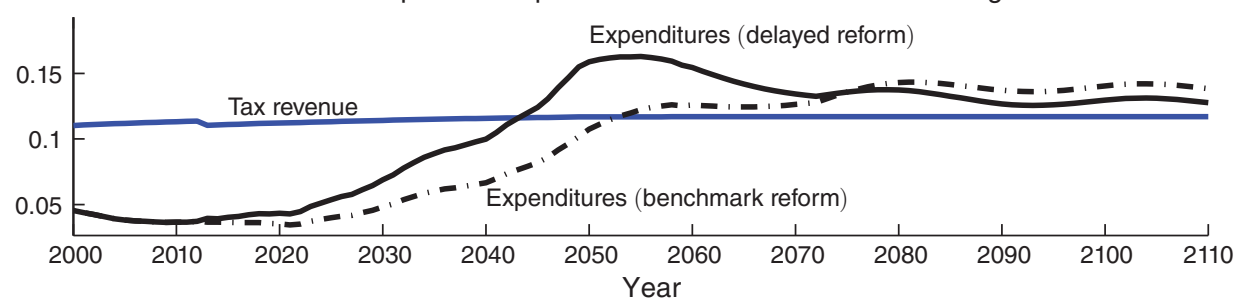

Panel C. Government debt as a share of urban earnings

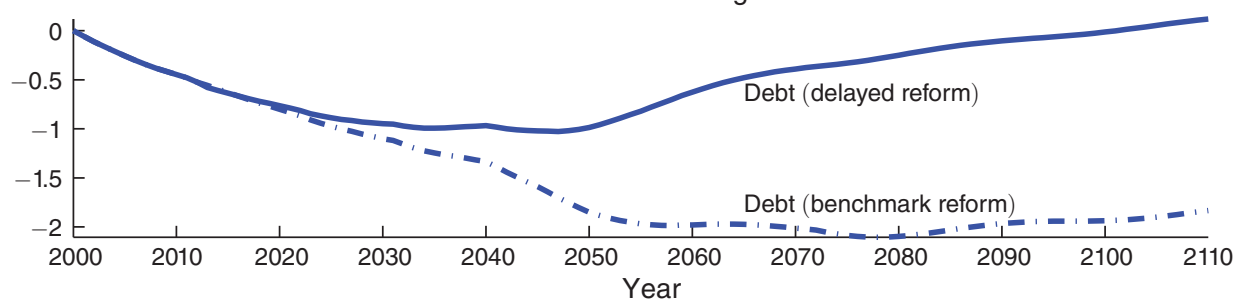

Figure 4. Pensions, Taxes, and Trust Fund: Benchmark versus Delayed Reform

Notes: Panel A shows the replacement rate $q_{t}$ for the benchmark reform (dashed line) versus the case when the reform is delayed until 2050. Panel B shows tax revenue and expenditures expressed as a share of aggregate urban labor income (benchmark reform is dashed and the delay-until-2050 is solid). Panel C shows the evolution of government debt expressed as a share of aggregate urban labor income (the benchmark reform is dashed and the delay-until-2050 is solid). Negative values indicate a surplus.

the World Bank (see Sin 2005, 30). Alternatively, if one were to keep the replacement rate constant at the initial 60 percent and to increase taxes permanently so as to satisfy (11), then $\tau$ should increase from 20 to 30.7 percent as of year 2013 .

Figure 4 shows the evolution of the replacement rate by cohort under the benchmark reform (panel A, dashed line). The replacement rate is 78 percent until 1997 and then falls to 60 percent. Under the benchmark reform, it falls further to 39.1 percent in 2013, remaining constant thereafter. Panel B (dashed line) shows that such a reform implies that the pension system runs a surplus until 2052. The government builds up a government trust fund amounting to 210 percent of urban labor earnings by 2080 (panel C, dashed line). The interests earned by the trust fund are used to finance the pension system deficit after 2052.23

\footnotetext{
${ }^{23}$ Note that in panel $\mathrm{C}$ the government net wealth (excluding debt) is falling sharply between 2000 and 2020 when expressed as a share of urban earnings, even though the government is running a surplus. This is because urban earnings are rising very rapidly due to both high wage growth and growth in the number of urban workers.
} 


\section{Alternative Pension Reforms}

The theoretical analysis of Section I shows that a social planner with a discount factor no higher than $(1+g) / R$ (where, recall, $g$ is the long run growth rate, and not the transitional wage growth in an emerging economy) wants to redistribute in favor of the poorer earlier generations. The benchmark reform, to the opposite, reduces current pension payments drastically in order to guarantee the financial sustainability of the pension in the long run.

In this section, we consider a set of alternative reforms that are also financially sustainable, but distribute the costs and benefits of the adjustment in a different way from the benchmark reform. We first consider a set of theoretically motivated reforms along the lines of Proposition 1 and Corollary 2. This provides a useful benchmark quantifying how large welfare gain one could possibly achieve through intergenerational redistribution. Then, we consider a set of policy reforms entailing less radical changes of the existing rules. We view these experiments as useful because they correspond closely to actual reforms that have been on the agenda of the policy debate in China and other countries. Each alternative policy reform is introduced as a surprise. Namely, agents expect the benchmark reform, but when 2013 arrives, unexpectedly, they learn that a different reform will take place. Subsequently, perfect foresight is assumed. This assumption is not essential. The main results are qualitatively identical and quantitatively very similar if one assumes that all reforms are perfectly anticipated in year 2000 .

\section{A. The Welfare Criterion}

Since the main goal of our analysis is to quantify the welfare implications of different reforms, we first introduce a welfare criterion analogous to that used in the theoretical analysis of Section I. To this end, we measure, for each cohort, the equivalent consumption variation of each alternative reform relative to the benchmark reform. Namely, we calculate what (percentage) change in lifetime consumption would make agents in each cohort indifferent between the benchmark and the alternative reform. ${ }^{24}$ We then aggregate the welfare effects of different cohorts by means of a utilitarian social welfare function, where the weight of the future generation decays geometrically with a constant factor $\phi$, as in Section IB. The planner's welfare function includes utilities of all agents alive in 2013 and the objective function is evaluated in year 2013 (decisions made before 2013 are held constant). Then, the equivalent variation is given by the value $\omega$ solving

$$
\sum_{t=1935}^{\infty} \mu_{t} \phi^{t} \sum_{j=0}^{J} \beta^{j} u\left((1+\omega) c_{t, t+j}^{B E N C H}, h_{t, t+j}^{B E N C H}\right)=\sum_{t=1935}^{\infty} \mu_{t} \phi^{t} \sum_{j=0}^{J} \beta^{j} u\left(c_{t, t+j}^{*}, h_{t, t+j}^{*}\right)
$$

\footnotetext{
${ }^{24}$ Note that we measure welfare effects relative to increases in lifetime consumption even for people who are alive in 2012. This approach makes it easier to compare welfare effects across generations.
} 
where superscripts $B E N C H$ stand for the allocation in the benchmark reform and asterisks stand for the allocation in the alternative reform. ${ }^{25}$

The planner experiences a welfare gain (loss) from the alternative allocation whenever $\omega>0(\omega<0)$. We shall consider two particular values of the intergenerational discount factor, $\phi$. First, $\phi=(1+g) / R$, which is the benchmark discount factor discussed in Section IB (see Proposition 1 and Corollary 2) corresponding to a planner who prefers zero intergenerational redistribution in steady state. Since in our calibration $R=1.025$ and $g=0.02$, such a planner has an annual discount rate of 0.5 percent, a small number relative to standard calibrations. ${ }^{26}$ For this reason, we label the planner with $\phi=(1+g) / R$ as the low-discount planner. As a robustness, following Nordhaus (2007), we consider the case of $\phi=R^{-1}$, namely, the planner discounts future utilities at the market interest rate. We label such a planner as the high-discount planner. Relative to the low-discount benchmark, the high-discount planner will demand more intergenerational redistribution in favor of the earlier generations.

\section{B. Theory-Driven Reforms}

In this section, we compute the pension systems that implement the optimal policies of a low-discount planner, and compare it with the benchmark reform. In addition to the unconstrained optimum corresponding to Proposition 1 and labeled "first best," we consider (i) a policy where the pension system is constrained to have nonnegative pensions (labeled "second best"), and (ii) a more restrictive environment in which the planner cannot increase the generosity of the pension system relative to the existing rules, namely, future replacement rates cannot exceed 60 percent (whereas the existing rules apply for the agents already retired in 2013).

The two panels of Figure 5 show, respectively, the sequence of cohort-specific replacement rates in each of the three alternative reforms (panel A), and the consumption equivalent welfare gain for each cohort relative to the benchmark reform (panel B). The panels display only generations retiring after 2000. ${ }^{27}$

Consider the first-best reform. The replacement rate is 230 percent for the cohort retiring in 2013. Thereafter, it falls roughly linearly with the retirement date until it reaches -23.7 percent in 2075 . There are huge welfare gains for the transition generations-exceeding 100 percent for those retiring between 2013 and 2033. The welfare gains fall over time and converge to -8.7 percent for the cohort retiring after 2075. All generations retiring before 2062 gain from the reform. The welfare gain

\footnotetext{
${ }^{25}$ Note that we sum over agents alive or yet unborn in 2012. The oldest person alive became an adult in 1935, which is why the summations over cohorts indexed by $t$ start from 1935 .

${ }^{26}$ Most macroeconomic studies assume discount rates in the range of 3-5 percent. In the debate on global warming, Nordhaus suggests a 3 percent discount rate. Stern argues that this is ethically indefensible, and proposes to apply a 0.1 percent discount rate, although many economists criticize this low rate for yielding counterfactual implications (for instance, governments should accumulate assets rather than run debt). In this paper, we emphasize the quantitiative normative prediction of the model when it is calibrated with the discount rates of 0.5 and 2.5 percent, which we regard as a conservative criterion.

${ }^{27}$ The efficient scheme involves large transfers to the generations already retired. For instance, those retiring in 1990 receive a replacement rate equal to 738 percent in the first-best and to 698 percent in the second-best reform.
} 
Panel A. Replacement rates in theory-driven reforms

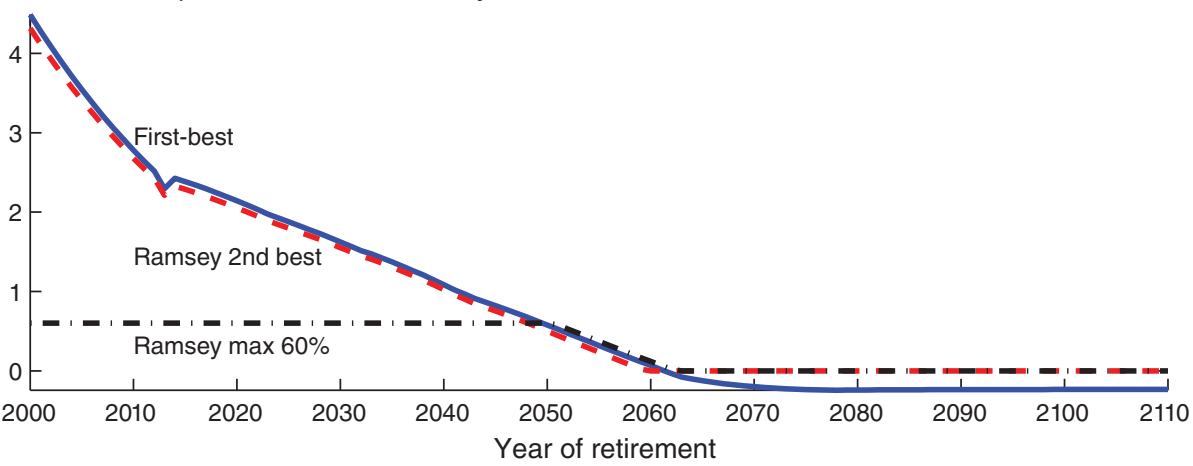

Panel B. Welfare gains of theory-driven reforms

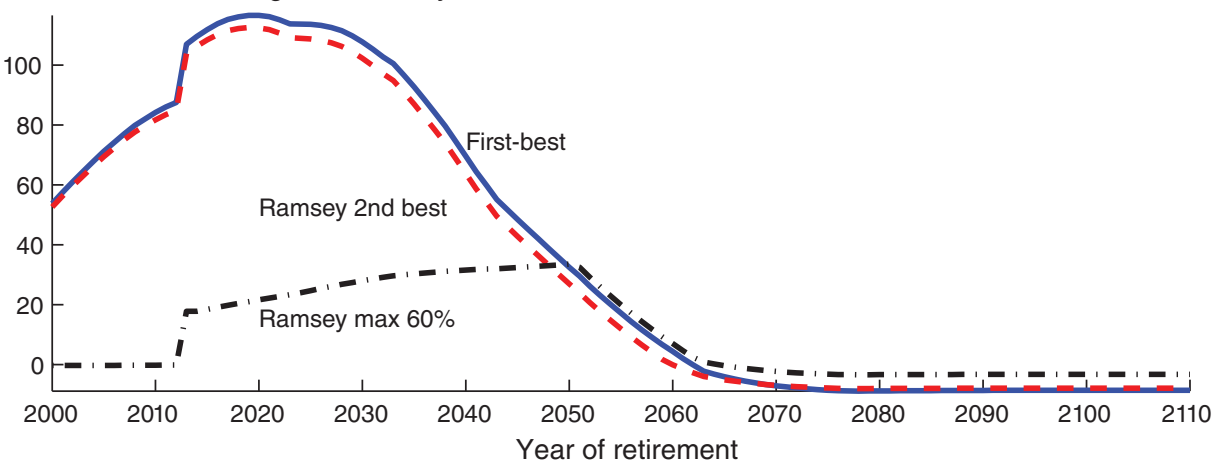

Figure 5. Optimal Policy: Welfare Gains and Replacement Rates

Notes: Panel A plots the sequence of cohort-specific replacement rates in the first-best reform (solid line), second-best Ramsey reform with nonnegative pensions (dashed line), and Ramsey reform where future replacement rates are bounded between 0 and 60 percent (dash-dotted line). Panel B plots the corresponding consumption equivalent welfare gains for each cohort.

accruing to the low-discount planner is 3.7 percent of consumption. In the case of the high-discount planner the gain is a staggering 41.7 percent.

The second best reform (subject to nonnegative benefits) yields a similar picture, although it delivers slightly lower replacement rates for the transition generations, reaching zero for cohorts retiring after 2060. Taxes are zero for cohorts retiring before 2060, implying that the system builds up a debt that is financed by taxes on future generations. In steady state, the tax rate reaches 10.2 percent. The welfare gain to the low-discount planner amounts to 3.6 percent of consumption. ${ }^{28}$

Finally, consider the constrained Ramsey allocation where the replacement rate must stay between 0 and 60 percent. In this case, the replacement rate is exactly 60 percent for all cohorts retiring until 2050. The replacement rate falls and reaches

\footnotetext{
${ }^{28}$ We computed the first- and second-best (and the corresponding benchmark) reforms under the alternative assumption that $A_{2013}=0$. The results are similar. The welfare gain of the first-best increases from 3.75 to 3.79 percent, while the second best delivers smaller gains ( 3.67 vs. 3.64 percent). The planner delivers positive pensions until 2058, and the steady-state tax rate reaches 10.2 percent.
} 
zero in 2063 . The steady-state taxes are lower (5.7 percent) because the pension system is less generous with the transition generation and does not build up such a large debt as in the previous case. The welfare gain to the low-discount planner is now substantially lower but still significant, being equal to 2 percent of consumption.

In conclusion, the quantitative normative analysis of this section has shown that even a planner with a very high weight on future generations would use the pension system to implement a radical intergenerational redistribution in spite of the averse demographics.

\section{Policy-Driven Reforms}

The benchmark reform achieves financial balance through a draconian permanent reduction in pension entitlements for all agents retiring after 2012. The analysis in Section IIIB shows that such adjustment puts too large a burden on current generations relative to the normative benchmark.

The optimal pension policies discussed above are informative about how to improve on the benchmark reform, but arguably difficult to implement. For instance, much of the current debate focuses on whether reforms reducing the generosity of the system are urgent or can be postponed, and on whether China should adopt rules that nudge the system in a more funded direction.

In this section, we consider a set of alternative sustainable reforms that speak more directly to the policy debate, and that would alter less radically the existing rules. We consider three types of reforms:

- Delayed reform: we assume that the current rules are kept in place until period $T$ (where $T>2013$ ), in the sense that the current replacement rate $\left(q_{t}=60\right.$ percent $)$ applies for those who retire until period $T$, and taxes remain at 20 percent. Thereafter, the replacement rates are adjusted permanently so as to satisfy (11). Note that, since the current system is not financially balanced, a delay requires a larger cut in replacement rates after $T$. Year $T$ is chosen optimally so as to maximize the planner's welfare. This reform entails a key aspect of the optimal policy: the replacement rate is decreasing over time, providing intergenerational distribution from the future richer generations to the current poorer transition generation.

- Fully-funded $(F F)$ reform: we replace the current transfer-based system with a mandatory saving-based scheme in 2013. In the FF reform scenario, defined benefit transfers are abolished in 2013. However, the government does not default on its outstanding liabilities (see footnote 30 for details). This reform entails an aspect of the optimal policy: it reduces the distortion caused by the social security tax, although it does not provide any intergenerational redistribution.

- Pay-as-you-go (PAYGO) reform: we impose an annual balanced budget requirement to the pension system, keeping the social security tax at 20 percent. The benefit rate is endogenously determined by the tax revenue (which is, in turn, affected by the demographic structure and endogenous labor supply). Given the demographic transition and the initially high wage growth, 
this reform yields high pensions to the earlier generations, and low pensions to the future ones-in line with the optimal policy.

Delayed Reform.-We start by computing the optimal delay of the benefit cut. The optimal $T$ for the low-discount planner turns out to be 2050. Namely, the current replacement rate continues to apply for all workers starting their employment before 2012, and the new lower replacement rate applies to workers starting their employment earliest 2012. This means that lower pensions will start being paid in 2050, and by 2090 all retirees will earn the new lower replacement rate.

Due to the delay, the fund accumulates initially a lower surplus, forcing a larger reduction of the replacement rate after 2050. Thus, relative to the benchmark reform, the delay shifts the burden of the adjustment from the current (poorer) generations to (richer) future generations.

Figure 4 describes the welfare gains of delaying the reform until 2050. Panel A shows that the post-reform replacement rate now falls to 36 percent, which is only 3.1 percentage points lower than the replacement rate granted by the benchmark reform. Panel B shows that the pension expenditure is higher than in the benchmark reform until 2075. Moreover, already in 2044 the system runs a deficit.

Figure 6 shows the welfare gains of four reforms relative to the benchmark, broken down by the year of retirement of each cohort. Consider the delayed reform experiment: There are large gains for agents retiring between 2013 and 2049, on average, over 15.9 percent of their lifetime consumption. The main reason is that delaying the reform enables the transition generation to share the gains from high wage growth after 2013, to which pension payments are (partially) indexed. All generations retiring after 2050 lose, although their welfare losses are quantitatively small, being less than 1.7 percent of their lifetime consumption. Relative to the first best, the delayed reform implies too little intergenerational redistribution from future to current generations. Moreover, it entails labor supply distortions that are absent in the first-best reform. Yet, the low-discount planner enjoys a 0.9 percent welfare gain, corresponding to roughly one quarter of the potential gain in the first best, and half of the welfare gain obtained in the planning allocation subject to the constraint that the replacement rate must lie between zero and 60 percent.

Figure 7 shows the welfare gains/losses of delaying the reform until year $T$. The figure displays two curves: in the upper curve, we have the consumption equivalent variation of the high-discount planner, while in the lower curve we have that of the low-discount planner. As discussed above, it is optimal for the low-discount planner to delay the reform until 2050. The same delay would yield a much larger welfare gain (6.4 percent) for the high-discount planner whose utility is increasing in the entire range plotted by the figure.

Fully Funded Reform.-Consider, next, switching to a FF system, i.e., a pure contribution-based pension system featuring no intergenerational transfers, where agents are forced to save for their old age in a fund that has access to the same rate of return as that of private savers. As long as agents are rational and have time-consistent preferences, and mandatory savings do not exceed the savings that agents would make privately in the absence of a pension system, a FF system is equivalent to no 


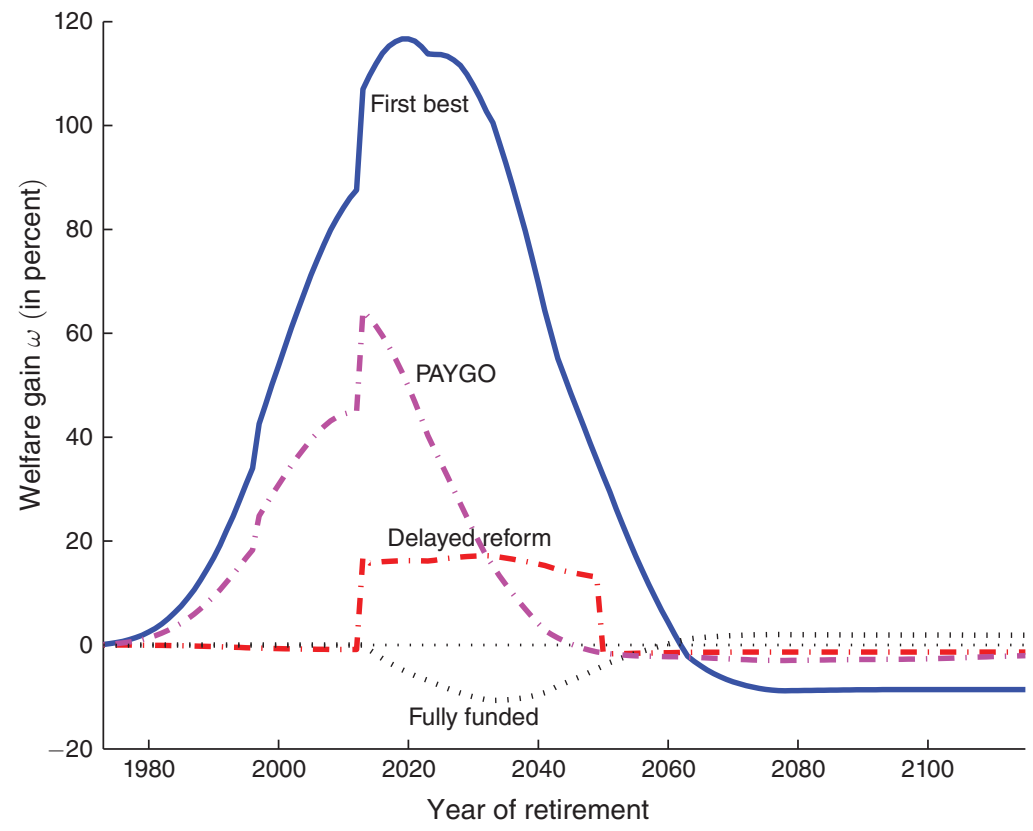

Figure 6. Welfare Gains of Policy-Driven Reforms

Notes: The figure shows welfare gains of the policy-driven alternative reforms relative to the benchmark reform for each cohort. For comparison, the welfare effects of the first-best policy is also plotted. The gains $(\omega)$ are expressed as percentage increases in consumption (see equation (12)).

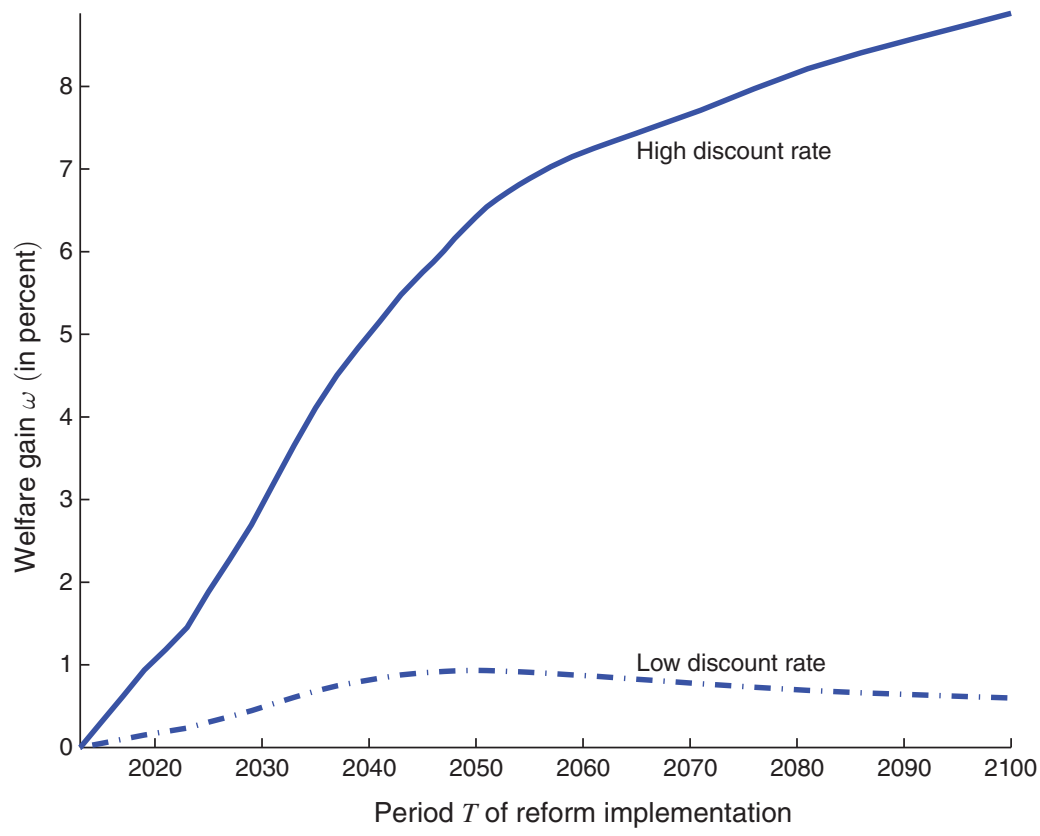

Figure 7. Welfare Gains of Delaying Reform (Utilitarian Planner)

Notes: The figure shows the consumption equivalent gain/loss accruing to a high-discount planner (solid line) and to a low-discount planner (dashed line) of delaying the reform until time $T$ relative to the benchmark reform. When $\omega>0$, the planner strictly prefers the delayed reform over the benchmark reform. 
Panel A. Tax revenue and pension expenditures as shares of urban earnings

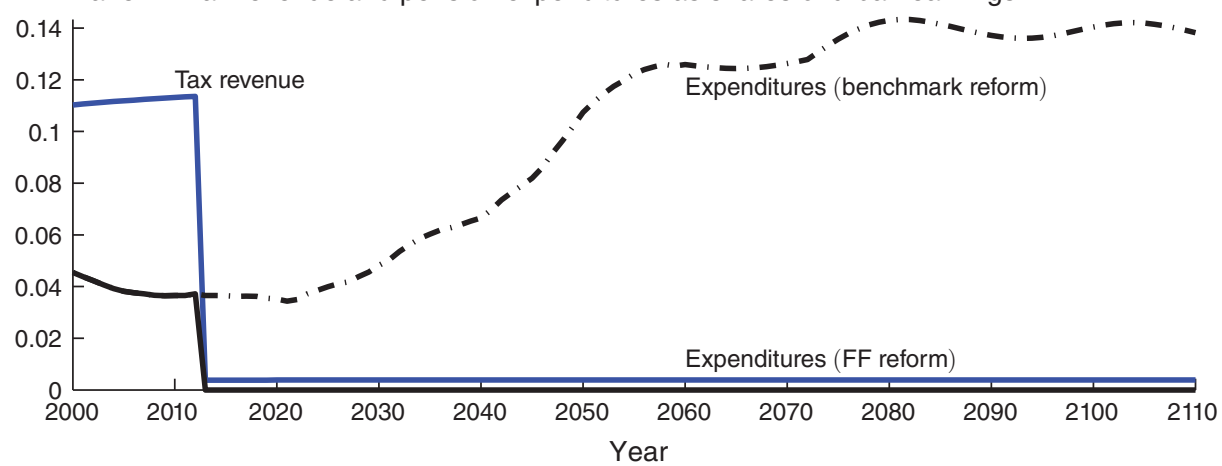

Panel B. Government debt as a share of urban earnings

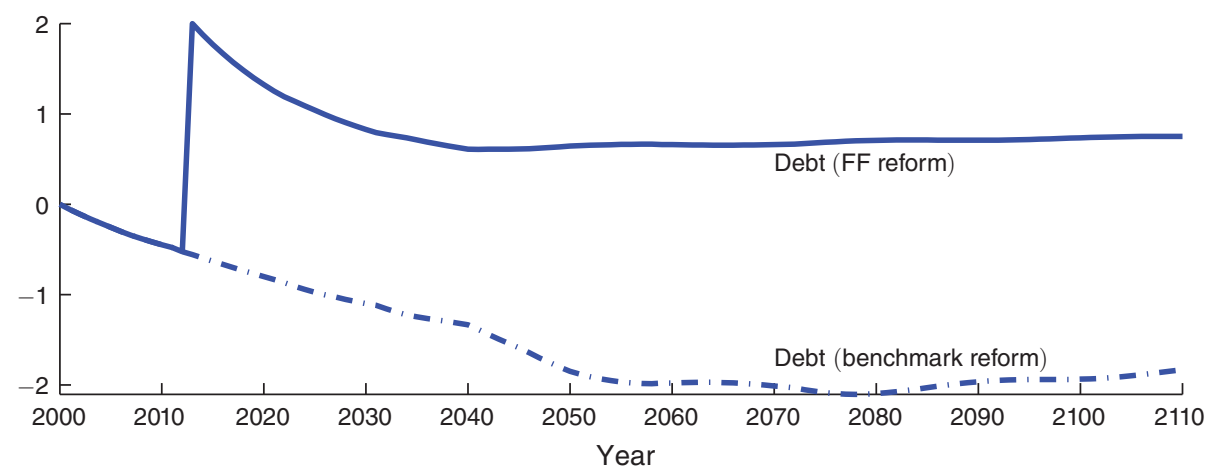

Figure 8. Pensions, Taxes, and Trust Fund: Benchmark vs. Fully-funded Reform

Notes: The figure shows outcomes for the fully funded reform (solid lines) versus the benchmark reform (dashed lines). Panel A shows the replacement rates. Panel B shows the government debt as a share of aggregate urban labor income.

pension system. ${ }^{29}$ As discussed above, the government does not default on existing claims: all workers and retirees who have contributed to the pension system are refunded the present value of the pension rights they have accumulated. ${ }^{30}$ Since the social security tax is abolished, the existing liabilities are financed by issuing government debt. This debt is rolled over and serviced by a constant labor income tax (implying that the outstanding debt level can fluctuate over time). This scheme is similar to that adopted in the 1981 pension reform of Chile.

Figure 8 shows the outcome of this reform. The old system is terminated in 2013, but people with accumulated pension rights are compensated as discussed above. To finance such a pension buy out scheme, government debt must increase to over 200 percent of urban labor earnings in 2013. A permanent 0.6 percent annual tax is needed to service the debt. The government debt first declines as a share of total

\footnotetext{
${ }^{29}$ Bohn (2011) shows that such equivalence breaks down in the presence of political or financial constraints. These aspects are ignored in our paper.

${ }^{30}$ In particular, people who have already retired are given an asset worth the present value of the pensions according to the old rules. Since there are perfect annuity markets, this is equivalent to the prereform scenario for those agents. People who are still working and have contributed to the system are compensated in proportion to the number of years of contributions.
} 
labor earnings due to high wage growth in that period, and then stabilizes at a level about 60 percent of labor earnings around 2040. Future generations live in a low-tax society with no intergenerational transfers.

As shown in Figure 6, the distributional effects are opposite to those of the delayed reforms. The cohorts retiring between 2013 and 2059 are harmed by the FF reform relative to the benchmark. There is no effect on earlier generations, since those are fully compensated by assumption. The losses are also modest for cohorts retiring soon after 2013, since these have earned almost full pension rights by 2013 . However, the losses increase for later cohorts and become as large as 10.6 percent for those retiring in 2030-2035. For such cohorts, the system based on intergenerational transfer is attractive, since wage growth is high during their retirement age (implying fast-growing pensions), whereas the returns on savings are low. Losses fade away for cohorts retiring after 2050 and turn into gains for those retiring after 2059. However, the long-run gains are modest.

The FF reform yields a 0.2 percent consumption equivalent gain for the lowdiscount planner. This small gain arises from two opposite effects: on the one hand, the FF reform reduces the labor supply distortion, due to the lower taxes; on the other hand, it does worse than the benchmark reform in terms of the intergenerational redistribution desired by the planner. As the high-discount planner values intergenerational redistribution more than the low-discount planner, the former strictly prefers the benchmark over the FF reform, with a consumption equivalent discounted loss of 3.3 percent.

Pay-As-You-Go Reform.-The delayed reform experiment was restricted by design to yield a two-tier replacement rate (prereform and postreform) with a maximum replacement rate of 60 percent for the generations before the reform. In contrast, the optimal policy features a declining benefit sequence with very high replacement rates for the initial generations (particularly, for those already retired). In an aging economy, a pure PAYGO system would precisely yield a smooth decline in replacement rates. However, relative to the optimal policy, a PAYGO entails tax distortions that the planner dislikes, as we showed.

In this section, we consider the effect of switching to a PAYGO. We maintain the contribution rate fixed at $\tau=20$ percent and assume that the benefits equal the total contributions in each year. Therefore, the pension benefits $b_{t}$ in period $t$ are endogenously determined by the following formula: ${ }^{31}$

$$
b_{t}=\frac{\tau \sum_{j=0}^{J_{W}} \mu_{t-j} s_{j} \varpi_{j} \eta_{t-j} w_{t} h_{t-j, t}}{\sum_{j=J_{W}+1}^{J} \mu_{t-j} s_{j}}
$$

Figure 9 shows the outcome of this reform. Panel A reports the pension benefits as a fraction of the average earnings by year. Note that this notion of replacement

\footnotetext{
${ }^{31}$ Note that the pension system has accumulated some wealth before 2012 . We assume that this wealth is rebated to the workers in a similar fashion as the implicit burden of debt was shared in the fully funded experiment. In particular, the government introduces a permanent reduction $\delta$ in the labor income tax, in such a way that the present value of this tax subsidy equals the 2012 accumulated pension funds. In our calibration, we obtain $\delta=0.59$ percent.
} 

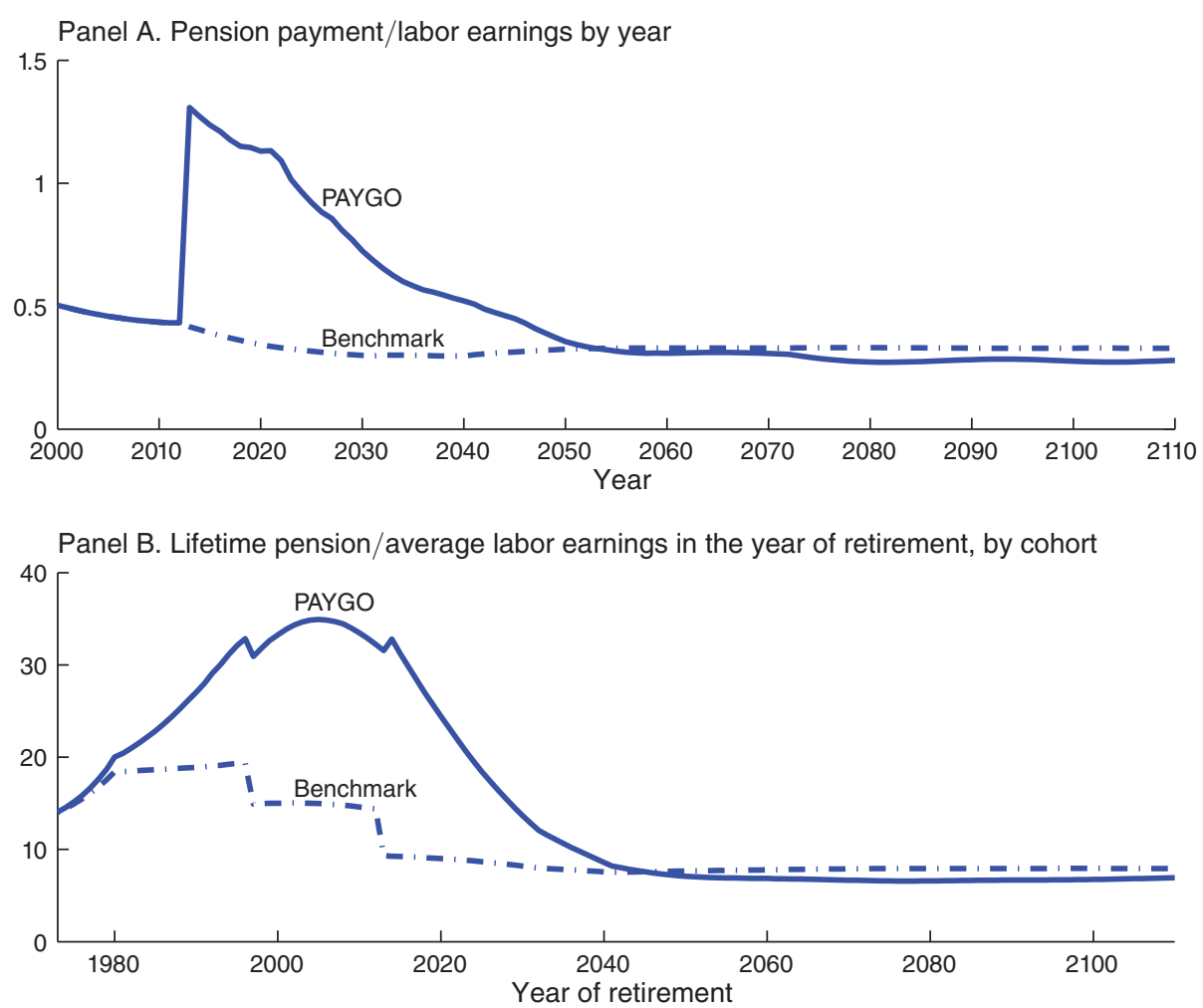

Figure 9. Replacement Rates under PAYGO versus Benchmark Reform

Notes: Panel A shows the average pension payments in year $t$ as a share of average wages in year $t$ for the PAYGO (solid) and the benchmark reform (dashed line). Panel B shows the ratio of the lifetime pensions (discounted to the year of retirement) to the average labor earnings just before retirement for each cohort.

rate is different from that used in the previous experiments (panel A of Figures 4 and 8); there the replacement rate was cohort specific and was computed according to equation (9) by the year of retirement of each cohort. Until 2053, the PAYGO reform implies larger average pensions than does the benchmark reform.

Panel B shows the lifetime pension as a share of the average wage in the year of retirement, by cohort. This is also larger than in the benchmark reform until the cohort retiring in 2045. We should note that, contrary to the previous experiments, which were neutral vis-à-vis cohorts retiring before 2013, here even earlier cohorts benefit from the PAYGO reform, since the favorable demographic balance yields higher pensions than what they were promised. This can be seen in panel B of Figure 9 and Figure 6. Welfare gains are very pronounced for all cohorts retiring before 2045, especially so for those retiring right after 2013, who would suffer a significant pension cut in the benchmark reform. These cohorts retire in times when the old-age dependency ratio is still very low, so benefits are large. Generations retiring after 2045 instead lose.

Due to the strong redistribution in favor of poorer early generations, in spite of the tax distortion, the utilitarian welfare is significantly higher under the PAYGO reform than in the benchmark reform, for both a high- and low-discount planner. The 
consumption equivalent gains relative to the benchmark reform are, respectively, 12.4 and 1.6 percent for urban workers. These gains are larger than under all alternative reforms (including delayed and FF reform).

\section{Sensitivity Analysis}

In this section, we study how the main results of the previous section depend on structural features of the model economy: wage growth, population dynamics, and interest rate. We also show that the results are robust to modeling the pension system as comprising two separate budgets for the defined benefit and individual account component. We refer to the calibration of the model used in the previous section as the baseline economy. Table 1 summarizes the results discussed throughout this section. Each column reports the welfare effects of different reforms accruing to the high- and low-discount planner relative to a particular environment.

\section{A. Lower Wage Growth}

In the analysis above, Chinese wages grow fast over the next 25 years, and converge to 54 percent of the US level by 2040. Thereafter, the gap remains constant. In the theoretical analysis of Section I, the sequence of fast convergence followed by a growth slowdown is the key source for the welfare gain of intergenerational redistribution. In this section, we consider two alternative wage scenarios; (i) zero growth over and above the 2 percent long-run growth so the long-run wages are lower than in the baseline scenario (no convergence), and (ii) slower wage growth, i.e., a slower convergence to the same wage level as in the baseline scenario. As we shall see, the welfare implications of pension reforms differ sharply across these two alternative wage growth scenarios.

Scenario 1: Low Wage Growth (No Convergence).- - In the no-convergence scenario, we assume wage growth to be constant and equal to 2 percent after 2013. In this case, the benchmark reform implies a replacement rate of 40.4 percent. ${ }^{32}$

The welfare effects of the alternative reforms (assuming the low wage growth) are displayed in the first row of panels in Figure 10 and aggregated in the second row of Table 1. In general, the welfare gains of the earlier generations relative to the benchmark 2013 reform are significantly smaller than in the baseline wage growth economy. For instance, if the reform is delayed until 2050 (yielding a replacement rate of 37 percent) the cohorts retiring between 2013 and 2049 experience a welfare gain ranging between 8.3 and 9.8 percent. The cost imposed on future generations remains similar in magnitude to that of the baseline economy. For the low-discount planner, there is a tiny loss from delaying. The high-discount planner continues to enjoy a positive welfare gain (3.3 percent), albeit significantly lower than in the

\footnotetext{
${ }^{32}$ Note that in the low wage growth economy, the present value of the pension payments is lower than in the baseline economy, since pensions are partially indexed to the wage growth. Thus, pensions are actually lower, in spite of the slightly higher replacement rate.
} 
Table 1 -Welfare Gains of Policy-Driven Reforms, Alternative Scenarios

\begin{tabular}{|c|c|c|c|c|c|c|c|c|}
\hline \multirow[b]{2}{*}{ Planner's discount rate } & \multicolumn{2}{|c|}{ Delayed until 2050} & \multicolumn{2}{|c|}{ Delayed until 2100} & \multicolumn{2}{|c|}{ Fully funded } & \multicolumn{2}{|c|}{ PAYGO } \\
\hline & high & low & high & low & high & low & high & low \\
\hline Baseline parameterization & 6.4 & 0.9 & 8.9 & 0.6 & -3.3 & 0.2 & 12.4 & 1.6 \\
\hline Slow wage convergence & 6.4 & 1.0 & 9.0 & 0.7 & -3.6 & 0.1 & 12.3 & 1.7 \\
\hline Low wage growth & 3.3 & -0.1 & 5.6 & -0.4 & -0.6 & 0.8 & 5.0 & -0.1 \\
\hline Low fertility & 8.5 & 3.2 & 11.2 & 0.5 & -2.6 & -0.5 & 14.9 & 4.8 \\
\hline Slow migration & 6.5 & 0.9 & 8.7 & 0.6 & -3.3 & 0.2 & 11.5 & 1.6 \\
\hline High interest rate & 3.2 & -0.1 & 4.9 & -0.5 & 0.4 & 0.5 & 9.5 & -0.1 \\
\hline Two separate pillars & 6.2 & 1.0 & 7.8 & 0.8 & -2.2 & -0.1 & 7.6 & 1.2 \\
\hline
\end{tabular}

Note: The table summarizes the welfare effects measured in percent of consumption (equivalent variation) for the high- and low-discount rate planners of alternative pension reforms relative to the benchmark 2013 reform.

Panel A. Low wage growth
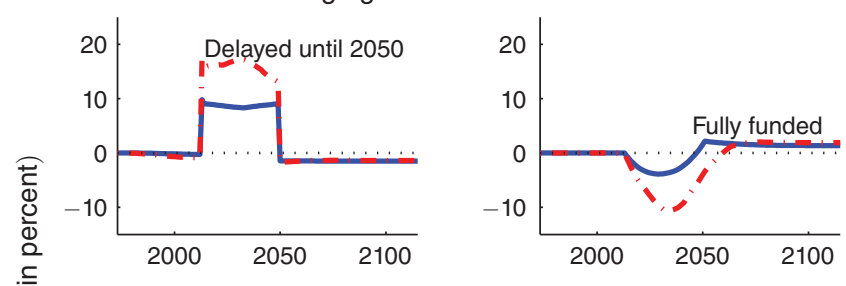

Panel B. Slow wage convergence
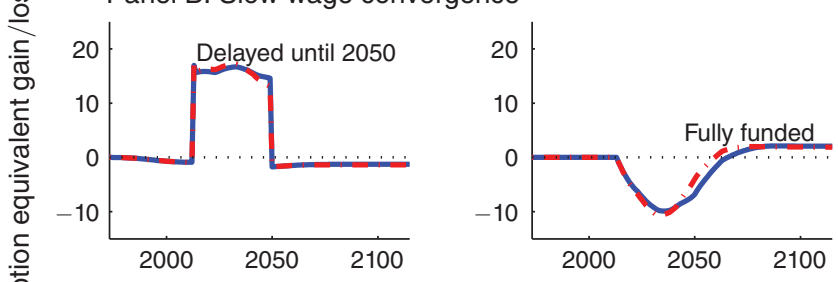

Panel C. Low fertility

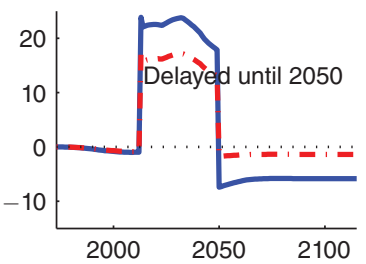

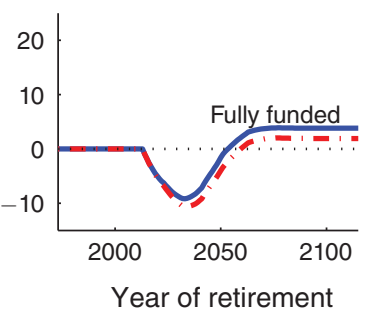
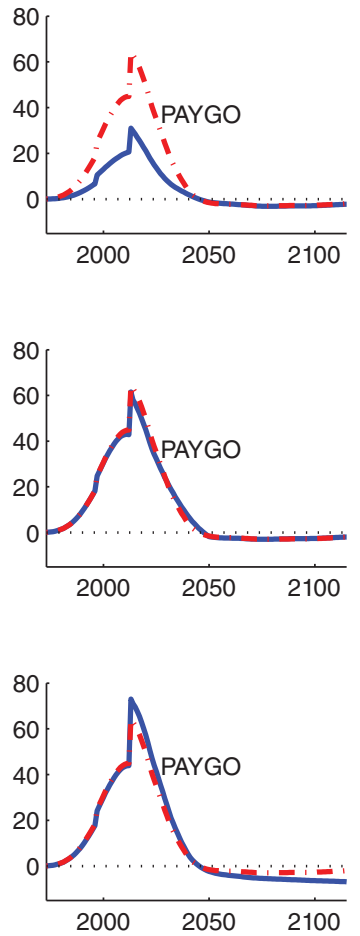

Figure 10. Sensitivity Analysis: Welfare Gains by Cohorts under Different Scenarios

Notes: The figure shows consumption equivalent gains/losses accruing to different cohorts in three alternative scenarios. The top panels refer to the slow wage converge scenario of Section IVA. The middle panels refer to the low wage growth (no convergence) scenario of Section IVA. The bottom panels refer to the low fertility scenario of Section IVB. In each panel, the dashed lines refer to the welfare gains under the benchmark calibration (see Section III). The left-hand panels show the consumption equivalent gains/losses associated with delaying the reform until 2050 (solid lines). The center panels show the consumption equivalent gains/losses associated with a fully funded reform (solid lines). The right-hand panels show the consumption equivalent gains/losses associated with a PAYGO reform (solid lines). 
baseline economy. This is not surprising, since the high-discount planner wants a declining replacement rate sequence even in steady state (see Proposition 1).

As in the baseline case, the FF alternative reform harms earlier cohorts, whereas it benefits all cohorts retiring after 2046. However, the relative losses of the earlier cohorts are significantly smaller than in the baseline economy. For instance, the cohort that is most negatively affected by the FF reform suffers a loss of 3.9 percent in the low wage growth economy, compared to a 10.7 percent loss in the baseline economy. The low-discount planner would now prefer the FF reform over any of the alternatives - the welfare gain arising from the reduction in the tax wedge. Finally, the large welfare gains from the PAYGO alternative reform by and large vanish. The low-discount planner would now prefer the benchmark reform to the PAYGO reform.

Scenario 2: Slower Convergence.-In this scenario, we assume an annual wage growth of 4 percent until 2050, and 2 percent thereafter. From 2050 and onward, the wage gap between China and the US is 54 percent, as in the baseline scenario.

The results of this experiment are quantitatively similar to the baseline case. Delaying the reform until 2050 requires lowering the replacement rate (relative to the benchmark 2013 reform) by 3 percentage points, as in the baseline wage growth scenario. The mid-left panel of Figure 10 plots the welfare gains/losses of generations retiring between 2000 and 2110 in the case of a delay of the reform until 2050. The continuous line refers to the slow wage growth scenario, whereas the dashed line refers to the baseline wage growth scenario, for comparison. From the social planner's standpoint, the net effect of delaying the reform is about the same: delaying the reform until 2050 delivers a consumption-equivalent welfare gain to the low (high) discount planner of 1.0 percent ( 6.4 percent), approximately the same as in the baseline scenario (see the third row of Table 1). ${ }^{33}$

The distribution of welfare gains in the FF and PAYGO experiments are essentially the same as in the baseline economy (see mid-center and mid-right panels of Figure 10). The PAYGO reform continues to dominate over all alternative options: a gain of 1.7 percent (12.3 percent) accrues the low (high) discount planner, compared to 1.6 percent (12.4 percent) in the baseline case.

Summary.-Wage convergence, a typical feature of emerging economies, is critical for the welfare gains of delaying a reform (or of switching to PAYGO as opposed to a FF system). It is the convergence per se rather than its speed that matters. We have considered two scenarios in which the average Chinese wage converges to 54 percent of the US level (an assumption that we regard as realistic, if conservative). In one case, convergence ends in 2040, in another it takes until 2050. The welfare implications of the alternative pension reforms considered are essentially identical. In contrast, the results are very different, even reversed, if we shut down the process of wage convergence. The comparison with a constant 2 percent

\footnotetext{
${ }^{33}$ For simplicity, we report the welfare gain of delaying the reform until the same year as was optimal in the baseline scenario, i.e., $T=2050$. However, with slower convergence the low-discount planner would find it optimal to delay the reform until 2052. The reason is that there are now more poor generations, and thus the planner would want to retain for longer the old generous replacement rate.
} 
wage growth scenario is especially revealing, since it is consistent with the standard assumption for pension analyses of developed economies.

\section{B. Lower Fertility}

Our forecasts are based on the assumption that the TFR will increase to 1.8 already in 2013. In this section, we consider an alternative lower fertility scenario along the lines of scenario 1 in Zeng (2007). In this case, the rural and urban TFRs are assumed to be 1.98 and 1.2 forever, implying an ever-shrinking total population. We view this as a lower bound to reasonable fertility forecasts. Next, we consider the welfare effects of the two alternative reforms. The three bottom panels of Figure 10 show the age distribution of the welfare effects and the gains are aggregated in the fourth row of Table 1.

Under this low-fertility scenario, the benchmark reform requires an even more draconian adjustment. The replacement rate must be set equal to 33.4 percent as of 2013. Delaying the reform is now substantially more costly. A reform in 2050 requires a replacement rate of 20.8 percent. The trade-off between current and future generations becomes sharper than in the baseline economy. On the one hand, there are larger gains for the cohorts retiring between 2013 and 2050 relative to the benchmark reform. On the other hand, the delay is more costly for the future generations. Aggregating gains and losses yields a gain for the low-discount planner of 3.2 percent, significantly larger than in the baseline economy. The FF reform exhibits larger losses than in the baseline model (even the low-discount planner prefers the benchmark to a FF reform). Moreover, the PAYGO reform yields larger gains than in the benchmark reform.

The reason for the larger gains from delaying the reform or switching to PAYGO is related to the fact that an economy with a low population growth is intrinsically poorer-which is reflected in a lower replacement rate in the benchmark case. Thus, sticking to the current rule ( 60 percent replacement rate for the earlier generations) implies more intergenerational redistribution than in the baseline economy. Since we have shown that the planner would like substantially larger replacement rates than 60 percent for the transition generation (see Figure 5), the low population growth relaxes the constraint for the planner. Thus the planner has a stronger preference for the delayed reform than in the richer baseline economy. A similar argument applies to the PAYGO reform.

\section{Slower Migration}

In the baseline case, the future age-specific migration rates are assumed to be time invariant. One might find it plausible that as urbanization proceeds, the migration rates will dwindle. We considered the following alternative experiment: we scaled down all migration rates to 55.2 percent of the baseline rates. This implies that the urban share of the total population is 67.6 percent in 2050 , compared to 80.9 percent in the baseline economy. We view this as a lower bound to a realistic description of the migration process. The results are quantitatively similar. In fact, the adjustment of the replacement rate required to achieve financial sustainability is slightly lower (a 
difference at the second digit) under slow migration than in the baseline scenario. Intuitively, in the initial years (i.e., until 2038), the migration flow is larger in the baseline scenario. However, after 2039, the slow migration scenario implies a larger migration flow (i.e., migrants per year), since more people are left in the rural areas and fertility remains high there (see Figure VIII in the online Appendix). Thus, in the slow migration scenario more migrants enter the urban sector when wages are already high and wages and pensions grow slowly. This makes for a larger contribution to the pension system than does a massive migration in the first period, when productivity is still low and wage and pension growth are higher. The comparison between alternative reforms yields similar results to the baseline model (see Table 1).

\section{High Interest Rate}

In the macroeconomic literature on pension reforms in developed economies, it is common to assume that the return on the assets owned by the pension fund is equal to the marginal return to capital. In this paper, we have calibrated the return on assets to 2.5 percent. However, the empirical rate of return on capital in China has been argued to be much higher (see discussion above). To get a sense of the role of this assumption, we now consider a scenario in which the interest rate is much higher-equal to 6 percent-between 2013 and 2050. ${ }^{34}$

There are two main differences between the scenarios with lower and higher interest rates. First, delaying the reform yields much smaller gains for the transitional generations, and in fact the low-discount planner is essentially indifferent between the benchmark reform and a delay until 2050. Second, the FF reform entails larger gains for the future generations and smaller losses for the current generations relative to the baseline calibration. As should be expected, when the interest rate is significantly higher than the average growth rate, the PAYGO system becomes less appealing, because the gains to current generations are smaller. In particular, the low-discount planner prefers the FF to the PAYGO reform.

\section{E. A Two-Pillar System with Perfect Separation}

In the analysis so far we have ignored an important institutional feature of the Chinese pension system, namely, the distinction (introduced with the 1997 reform) between a defined benefit (first pillar) component granting a 35 percent replacement rate and an individual account (second pillar) component estimated to pay an average 24.3 percent replacement rate (see Hu, Stewart, and Yermo 2007). As discussed above, our choice is motivated by the observation that the second pillar is largely notional, due to its undercapitalization. Although the two pillars are formally managed by different authorities, it is unclear to what extent the commitment not to engage in cross-subsidization is credible. This motivates our choice to treat the two pillars as being part of the same fungible pool of resources in the main analysis above. In this section, we explore the alternative assumption that individual

\footnotetext{
${ }^{34}$ See Song, Storesletten, and Zilibotti (2014) for an extensive discussion of the interest rate policy and capital market constraints in China.
} 
accounts belong to a totally separate budget and cannot be reneged upon. Thus, a sustainable reform can only pertain to the first pillar.

An important feature that must be taken into account is that the 1997 reform makes provisions for generations that have not accumulated significant individual accounts. For instance, a worker retiring in the year 2000 would only have had three years to build up her account at the time of the reform. Therefore, in order to capture the formal rules of the system, one must take into account that the move toward a two-pillar system is gradual and implies no default vis-á-vis the generations that contributed to the pre-reform system. More specifically, we assume that the new two-pillar system applies in its integrity to the generations entering the labor force after 1997, while the application is gradual for earlier generations. Although the details of the actual implementation are somewhat opaque, we assume a linearly declining first-pillar replacement rate from 78 percent in 1996 to 35 percent in 2035. Recall that in our model individual accounts can be ignored as they are equivalent to personal savings. We set the post-reform social security tax rate pertaining to the first pillar to 12 percent. This takes into account the high evasion rates that are common in China. ${ }^{35}$ This contribution rate starts applying already in 1998 and, as before, is kept constant over time and across experiments.

As in the baseline economy, the system based on the 1997 rules is not sustainable. In particular, while individual accounts are sustainable by construction, the first pillar is severely underfunded. In line with the analysis in Section II, we set as our benchmark a draconian reform that reduces the replacement rate suddenly and permanently to a new constant level in 2013 so as to meet the intertemporal budget constraint. The new replacement rate is in this case 23.2 percent. Note that this level is substantially lower than the statutory 35 percent replacement rate. Moreover, it applies right away to all generations retiring from 2013 and onward.

We contrast the benchmark reform to a delayed reform in which the statutory rules continue to apply until 2049. Namely, the replacement rate declines gradually to 35 percent in 2035 , and remains constant until 2049 when the sustainable reform is applied. The replacement rate that applies from 2050 and onwards is 21 percent, more than two percentage points less than in the draconian reform.

Panel A of Figure 11 displays the replacement rate by the year of retirement in the benchmark (dotted line) and delayed (solid line) reform. Panel B of Figure 11 shows the associated welfare gains broken down by cohorts. Relative to the baseline economy of Section I, which does not distinguish between the two pillars, there are now larger gains for the cohorts retiring earlier than 2028, and smaller (but still substantial) gains for cohorts retiring 2028-2049. The reason is that the statutory replacement rate in the two pillar system declines gradually, so the older cohorts have more to gain from the delay than in the baseline economy. The consumption equivalent gain for the low-discount planner is now marginally larger. The comparison between the benchmark reform and other alternatives (fully-funded, PAYGO)

\footnotetext{
${ }^{35}$ Recall that the statutory contribution rates for the first and second pillars are 20 percent and 8 percent, respectively. We assume there is tax evasion only for the first pillar. The assumption is based on the substitutability between wages and contributions to the second pillar under a fully consolidated individual account. This implies an actual contribution rate of 12 percent to the first pillar.
} 
Panel A. Replacement rate by year of retirement

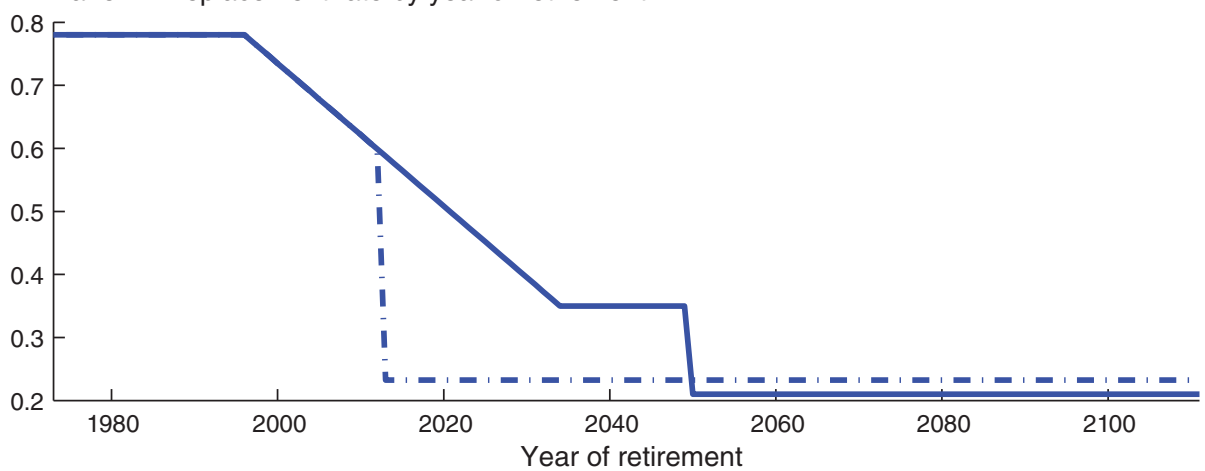

Panel B. Welfare gains of delayed reforms by year of retirement

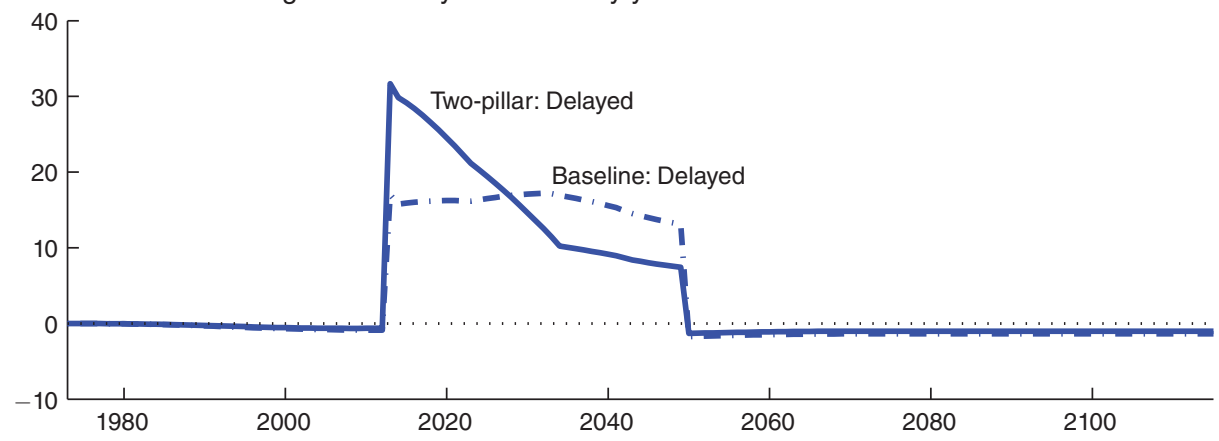

Figure 11. Sensitivity Analysis: Reform of Two-Pillar Pension System

Notes: Panel A shows the replacement rate $q_{t}$ for the two-pillar benchmark reform (dashed line) versus the case when the reform of the two-pillar system is delayed until 2050 (solid line). Panel B shows the welfare gains of delaying the reform of the two-pillar system relative to the two-pillar benchmark reform for each cohort (solid line). It also reports, for comparison, the welfare gain of delaying the reform in the baseline economy (dashed line, cf. Figure 4). The gains $(\omega)$ are expressed as percentage increases in consumption (see equation (12)).

yield similar results to the baseline economy: the PAYGO yields a 1.2 percent welfare gain, whereas the FF reform is approximately equivalent to the benchmark draconian reform (see the last row of Table 1).

We conclude that our results are qualitatively and quantitatively robust to modelling the Chinese pension system more closely to its statutory rules, assuming full commitment on individual accounts.

\section{Rural Pension}

The vast majority of people living in rural areas are not covered by the current Chinese pension. In accordance with this fact, we have so far maintained the assumption that only urban workers are part of the pension system. In this section, to contribute to the lively policy debate on this issue, we study the welfare implications of extending the system to rural workers.

Although a rural and an urban pension system could, in principle, be separate programs, we assume here that there is a consolidated intertemporal budget constraint, namely, the government can transfer funds across the rural and urban budgets. This 
is consistent with the observation that the modest rural pension system that China is currently introducing is heavily underfunded, suggesting that the government implicitly anticipates a resource transfer from urban to rural areas. The modified consolidated government budget constraint then becomes

$$
\begin{aligned}
A_{0}+\sum_{t=0}^{\infty} R^{-t}( & \sum_{j=0}^{J_{W}} \varpi_{j}\left[\tau_{t} \mu_{t-j} s_{j} w_{t} h_{t-j, t}+\tau_{t}^{r} \mu_{t-j}^{r} s_{j}^{r} w_{t}^{r} h_{t-j, t}^{r}\right] \\
& \left.-\sum_{j=J_{W}+1}^{J}\left[\mu_{t-j} s_{j} b_{t-j, t}+\mu_{t-j}^{r} s_{j}^{r} b_{t-j, t}^{r}\right]\right) \geq 0,
\end{aligned}
$$

where superscripts $r$ denote variables pertaining to the rural areas, whereas urban variables are defined, as above, without any superscript.

We assume the rural wage rate to be 54 percent of the urban wage in 2000, consistent with the empirical evidence from the China Health and Nutrition Survey. The annual rural wage growth is assumed to be on average 4.1 percent between 2000-2024, and 2 percent thereafter (see Figure VI in the online Appendix).

We consider two experiments. In the first (low-scale reform), we introduce a rural pension system with rules that are different from those applying to urban areas in 2013. This experiment mimics the rules of the new old-age programs that the Chinese government is currently introducing for rural areas (see online Appendix). Based on the current policies, we set the rural replacement rate $\left(q_{t}^{r}\right)$ and contribution rate $\left(\tau_{t}^{r}\right)$ to 20 and 6 percent, respectively. These rates are assumed to remain constant forever. Moreover, we assume that all rural inhabitants older than retirement age in 2013 are eligible for this pension. Introducing such a scheme in 2013 would worsen the fiscal imbalance. Restoring the fiscal balance through a reform in 2013 requires the replacement rate of urban workers to be cut to $q_{t}=37.8$ percent, i.e., 1.3 percentage points lower than in the benchmark reform without rural pensions. Hence, the rural pension implies a net transfer from urban to rural inhabitants.

A low-discount planner who only cares for urban households participating in the pension system would incur a welfare loss of less than 0.7 percent from expanding the pension system to rural inhabitants. In contrast, a low-discount planner who only cares for rural households would incur a welfare gain of 12 percent. When weighting rural and urban households by their respective population shares, one obtains an aggregate welfare gain of 1.7 percent relative to the benchmark reform.

The second experiment (drastic reform) consists of turning the Chinese pension system into a universal system, pooling all Chinese workers and retirees-in both rural and urban areas-into a system with common rules. As of 2013, all workers contribute 20 percent of their wage. In addition, the system bails out all workers who did not contribute to the system in the past. Namely, all workers are paid benefits according to the new rule even though they had not made any contribution in the past. Although rural and urban retirees have the same replacement rate, pension benefits are proportional to the group-specific wages (i.e., rural [urban] wages for rural [urban] workers). As in the benchmark reform above, the replacement rate is adjusted in 2013 so as to satisfy the intertemporal budget constraint of the universal pension system. Although we ignore issues with the political and administrative 
feasibility of such a radical reform, this experiment provides us with an interesting upper bound of the effect of a universal system.

The additional fiscal imbalance from turning the system into a universal one is surprisingly small: the replacement rate must be reduced to $q_{t}=38$ percent from 2013 onward, relative to 39.1 percent in the benchmark reform. The welfare loss for urban workers participating in the system is very limited (marginally lower than in the low-scale reform). In contrast, there are sizable welfare gains for rural workers and for the urban workers who are not currently participating in the system (on average, 14.1 and 0.8 percent, respectively, if evaluated by a low-discount planner).

To understand why this reform can give so large gains with such a modest additional fiscal burden, it is important to emphasize that (i) the earnings of rural workers are, on average, much lower than those of urban workers; and (ii) the rural population is declining rapidly over time. Both factors make pension transfers to the rural sector relatively inexpensive. It is important to note that our calculations ignore any cost of administering and enforcing the system. In particular, the benefit would decrease if the enforcement of the social security tax in rural areas proves to be more difficult than in urban areas.

\section{Conclusions}

Pension systems have been a key instrument for sharing high growth across generations in Western economies after World War II and could potentially play the same role in emerging countries. However, the prospect of an adverse demographic transition threatens the fiscal sustainability of nonfunded pension systems. In this paper, we analyze the positive and normative effects of alternative pension reforms with the aid of a dynamic model calibrated to China.

A number of studies before us argue that China must reform its pension system to achieve long-run balance (see, e.g., Sin 2005; Dunaway and Arora 2007; Salditt, Whiteford, and Adema 2007; and Lu 2011). Our analysis concurs with this view, but shows that rushing into a draconian reform would have large unequalizing effects: it would harm current generations and only mildly benefit future generations. In a fast-growing society like China, this would imply dispensing with a powerful institution redistributing resources from richer future generations to poorer current ones. Even a planner with an annual discount rate as low as 0.5 percent would prefer an unfunded pay-as-you-go system to both an immediate sustainable reform and to a reform that pre-funds the pension system.

The results are subject to some caveats. First, financial sustainability could be aided by increasing the retirement age. In the working paper version, we show that increasing retirement age by six years would restore financial sustainability. However, this would not alter the desire to use the pension system to achieve intergenerational redistribution in favor of the earlier generations. Second, we do not consider the effects of pension reforms on future fertility (see Courdacier, Guibaud, and Jin 2013). Finally, we abstract from the crowding out effect of public pensions on within-family old-age care. We believe that extending the analysis in these directions would not overturn our main insights. Our results obtain in a standard OLG 
model that predicts that, in a mature economy with steady wage growth and perfect capital markets, a fully funded system outperforms an unfunded PAYGO system. This sharp contrast illustrates the general principle that mechanically transposing policy advice from mature to developing or emerging economies may be misleading (see Acemoglu, Aghion, and Zilibotti 2006).

\section{REFERENCES}

Abel, Andrew B., N. Gregory Mankiw, Lawrence H. Summers, and Richard J. Zeckhauser. 1989. “Assessing Dynamic Efficiency: Theory and Evidence." Review of Economic Studies 56 (1): 1-19.

Acemoglu, Daron, Philippe Aghion, and Fabrizio Zilibotti. 2006. "Distance to Frontier, Selection, and Economic Growth." Journal of the European Economic Association 4 (1): 37-74.

-Allen, Franklin, Jun Qian, and Meijun Qian. 2005. "Law, Finance, and Economic Growth in China." Journal of Financial Economics 77 (1): 57-116.

Almås, Ingvild, and Åshild Auglænd Johnsen. 2013. The Cost of Living in China: Implications for Inequality and Poverty. University of Oslo Economics Department Memorandum 06/2013.

Auerbach, Alan J., and Laurence J. Kotlikoff. 1987. Dynamic Fiscal Policy. Cambridge: Cambridge University Press.

Bai, Chong-En, Chang-Tai Hsieh, and Yingyi Qian. 2006. "The Return to Capital in China." Brookings Papers on Economic Activity 36 (2): 61-88.

Barr, Nicholas, and Peter Diamond. 2008. Reforming Pensions: Principles and Policy Choices. Oxford: Oxford University Press.

Barro, Robert J., and Jong-Wha Lee. 2013. "A New Data Set of Educational Attainment in the World, 1950-2010.” Journal of Development Economics 104: 184-98.

Bohn, Henning. 2011. "Should Public Retirement Plans be Fully Funded?" Journal of Pension Economics and Finance 10 (2): 195-219.

Buiter, Wilhelm, and Ebrahim Rahbari. 2011. "Global Growth Generators: Moving beyond Emerging Markets and BRIC." Citi Global Economics View. http://www.voxeu.org/article/global-growth-generators-moving-beyond-emerging-markets-and-brics (accessed April 20, 2011).

Cai, Fang, John Giles, and Xin Meng. 2006. "How well do children insure parents against low retirement income? An analysis using survey data from urban China." Journal of Public Economics 90 (12): 2229-55.

Calvo, Esteban, and John B. Williamson. 2008. "Old-age pension reform and modernization pathways: Lessons for China from Latin America.” Journal of Aging Studies 22 (1): 74-87.

-Chan, Kam Wing, and Will Buckingham. 2008. "Is China Abolishing the Hukou System?" China Quarterly 195: 582-606.

China Statistical Yearbook. Various Issues. National Bureau of Statistics of China.

Conesa, Juan C., and Carlos Garriga. 2008. "Optimal Fiscal Policy in the Design of Social Security Reforms." International Economic Review 49 (1): 291-318.

-Conesa, Juan C., and Dirk Krueger. 1999. "Social Security Reform with Heterogeneous Agents." Review of Economic Dynamics 2 (4): 757-95.

Courdacier, Nicolas, Stéphane Guibaud, and Keyu Jin. 2013. "Fertility Policies and Social Security Reforms in China." Unpublished.

Dollar, David, and Shang-Jin Wei. 2007. "Das (Wasted) Kapital: Firm Ownership and Investment Efficiency in China." National Bureau of Economic Research (NBER) Working Paper 13103.

Duan, Chengrong, and Yujing Sun. 2006. "Changes in the Scope and Definition of the Floating Population in China's Censuses and Surveys." Population Research 30 (4): 70-76.

Dunaway, Steven V., and Vivek B. Arora. 2007. "Pension Reform in China: The Need for a New Approach." International Monetary Fund (IMF) Working Paper 07/109.

- Feldstein, Martin. 1999. "Social Security Pension Reform in China." China Economic Review 10 (2): 99-107.

Feldstein, Martin, and Jeffrey Liebman. 2006. "Realizing the Potential of China's Social Security Pension System." China Economic Times, February 24.

-French, Eric. 2005. "The Effects of Health, Wealth, and Wages on Labour Supply and Retirement Behaviour." Review of Economic Studies 72 (2): 395-427.

-Ge, Suqing, and Dennis Yang. 2014. "Changes in China's Wage Structure." Journal of the European Economic Association 12 (2): 300-336. 
Goodkind, Daniel M. 2004. "China's Missing Children: The 2000 Census Underreporting Surprise." Population Studies 58 (3): 281-95.

Hu, Ying. 2003. "Quantitative Analysis of the Population Transfers from Rural Areas to Urban Areas." Statistical Research 7: 20-24.

Hu, Yu-Wei, Fiona Stewart, and Juan Yermo. 2007. "Pension Fund Investment and Regulation: An International Perspective and Implications for China's Pension System." http://www.oecd.org/ finance/private-pensions/39604854.pdf.

- Huang He, Selahattin Imrohoglu, and Thomas J. Sargent. 1997. "Two Computations To Fund Social Security." Macroeconomic Dynamics 1 (1): 7-44.

-Hurd, Michael D. 1989. "Mortality Risk and Bequests.” Econometrica 57 (4): 779-813.

-Johnson, D. Gale. 2003. "Provincial Migration in China in the 1990s." China Economic Review 14 (1): 22-31.

Kaplan, Greg, and Sam Schulhofer-Wohl. 2012. "Understanding the Long-Run Decline in Interstate Migration.” Federal Reserve Bank of Minneapolis Working Paper 697.

-Keane, Michael P. 2011. "Labor Supply and Taxes: A Survey." Journal of Economic Literature 49 (4): 961-1075.

Krueger, Dirk, and Felix Kubler. 2006. "Pareto-Improving Social Security Reform When Financial Markets Are Incomplete." American Economic Review 96 (3): 737-55.

Lavely, William. 2001. "First Impressions from the 2000 Census of China." Population and Development Review 27 (4): 755-69.

Lu, Jiehua. 2011. "Impacts of Demographic Transition on Future Economic Growth: China's Case Study." Paper presented at University of Zurich Conference China and the West 1950-2050: Economic Growth, Demographic Transition and Pensions, November 21.

- Nishiyama, Shinichi, and Kent Smetters. 2007. "Does Social Security Privatization Produce Efficiency Gains?" Quarterly Journal of Economics 122 (4): 1677-1719.

Nordhaus, William. 2007. "Critical Assumptions in the Stern Review on Climate Change." Science 317 (5835): 201-02.

Park, Albert, Yan Shen, John Strauss, and Yaohui Zhao. 2012. "Relying on Whom? Poverty and Consumption Financing of China's Elderly." In Aging in Asia: Findings From New and Emerging Data Initiatives, edited by James Smith and Malay Majmundar, 148-72. Washington, DC: National Academies Press.

Rogerson, Richard, and Johanna Wallenius. 2009. "Retirement in a Life Cycle Model of Labor Supply with Home Production." University of Michigan Working Paper 205.

Salditt, Felix, Peter Whiteford, and Willem Adema. 2007. "Pension Reform in China: Progress and Prospects." Organisation for Economic Co-operation and Development (OECD) Working Paper 53.

Sin, Yvonne. 2005. "China: Pension Liabilities and Reform Options for Old Age Insurance." World Bank Working Paper 2005-1.

Song, Zheng, Kjetil Storesletten, Yikai Wang, and Fabrizio Zilibotti. 2015. "Sharing High Growth across Generations: Pensions and Demographic Transition in China: Dataset." American Economic Journal: Macroeconomics. http://dx/doi.org/10.1257/mac.20130322.

-Song, Zheng Michael, Kjetil Storesletten, and Fabrizio Zilibotti. 2011. "Growing Like China." American Economic Review 101 (1): 196-233.

Song, Zheng Michael, Kjetil Storesletten, and Fabrizio Zilibotti. 2014. "Growing (with Capital Controls) Like China." International Monetary Review (IMF) Economic Review 62 (3): 327-70.

Song, Zheng Michael, and Dennis Tao Yang. 2010. "Life Cycle Earnings and the Household Saving Puzzle in a Fast-Growing Economy." http://faculty.chicagobooth.edu/workshops/macro/past/ pdf/101111.pdf.

-Storesletten, Kjetil. 2000. "Sustaining Fiscal Policy through Immigration.” Journal of Political Economy 108 (2): 300-323.

Yang, Juhua. 2011. "Population Change and Poverty among the Elderly in Transitional China." Unpublished.

Yang, Juhua, and Zhiguang Chen. 2010. "Economic Poverty among the Elderly in the Era of Family Change: A Quantitative and Qualitative Analysis." Chinese Journal of Population Research 34 (5): 51-67.

Zeng, Yi. 2007. "Options for Fertility Policy Transition in China." Population and Development Review 33 (2): 215-46.

Zhai, Zhenwu, and Wei Chen. 2007. "Chinese Fertility in the 1990s." Chinese Journal of Population Research 31 (1): 19-32.

Zhang, Guangyu, and Zhongwei Zhao. 2006. "Reexamining China's Fertility Puzzle: Data Collection and Quality over the Last Two Decades." Population and Development Review 32 (2): 293-321. 
Zhang, Junsen, Yaohui Zhao, Albert Park, and Xiaoqing Song. 2005. "Economic Returns to Schooling in Urban China, 1988 to 2001." Journal of Comparative Economics 33 (4): 730-52.

Zhang, Weimin, and Hongyan Cui. 2003. "Estimation of Accuracy of 2000 National Population Census Data." Chinese Journal of Population Research 27 (4): 25-35.

Zhou, Yixing, and Laurence J. C. Ma. 2003. "China's Urbanization Levels: Reconstructing a Baseline from the Fifth Population Census.” China Quarterly 173: 176-96. 


\section{This article has been cited by:}

1. Thomas Piketty, Li Yang, Gabriel Zucman. 2019. Capital Accumulation, Private Property, and Rising Inequality in China, 1978-2015. American Economic Review 109:7, 2469-2496. [Abstract] [View PDF article] [PDF with links]

2.Xianjuan Chen. 2019. Born like China, growing like China. Pacific Economic Review 24:2, 325-347. [Crossref]

3. Benxi Lin, Zongjian Lin, Yu Zhang, Weiping Liu. 2018. The Impact of the New Rural Pension Scheme on Retirement Sustainability in China: Evidence of Regional Differences in Formal and Informal Labor Supply. Sustainability 10:12, 4366. [Crossref]

4. Fatemeh Alyari, Nima Jafari Navimipour. 2018. Recommender systems. Kybernetes 47:5, 985-1017. [Crossref]

5. Yueqiang Zhao, Manying Bai, Peng Feng, Mengyuan Zhu. 2018. Stochastic Assessments of Urban Employees' Pension Plan of China. Sustainability 10:4, 1028. [Crossref]

6. Suqin Ge, Dennis Tao Yang, Junsen Zhang. 2018. Population policies, demographic structural changes, and the Chinese household saving puzzle. European Economic Review 101, 181-209. [Crossref]

7. Chadwick C. Curtis, Steven Lugauer, Nelson C. Mark. 2017. Demographics and aggregate household saving in Japan, China, and India. Journal of Macroeconomics 51, 175-191. [Crossref]

8. Anping Chen, Nicolaas Groenewold. 2017. An increase in the retirement age in China: the regional economic effects. Applied Economics 49:7, 702-721. [Crossref]

9. Qing Zhao, Zhen Li, Taichang Chen. 2016. The Impact of Public Pension on Household Consumption: Evidence from China's Survey Data. Sustainability 8:9, 890. [Crossref]

10. Patrick Georges, Aylin Seçkin. 2016. From pro-natalist rhetoric to population policies in Turkey? An OLG general equilibrium analysis. Economic Modelling 56, 79-93. [Crossref]

11. M. Doepke, M. Tertilt. Families in Macroeconomics 1789-1891. [Crossref]

12. O. Attanasio, A. Bonfatti, S. Kitao, G. Weber. Global Demographic Trends 179-235. [Crossref]

13. Bing Han, Lu Han, Guozhong Zhu. 2015. Housing Price and Fundamentals in a Transition Economy: The Case of Beijing Market. SSRN Electronic Journal . [Crossref]

14. Qingyuang Du, Shang-Jin Wei. 2015. A Darwinian Perspective on 'Exchange Rate Undervaluation'. SSRN Electronic Journal . [Crossref]

15. Kaiji Chen, Yi Wen. 2014. The Great Housing Boom of China. SSRN Electronic Journal . [Crossref] 